The Relationship between Market Structure and Innovation in Industry Equilibrium: A Case Study of the Global Automobile Industry

by

Aamir Rafique HASHMI Johannes VAN BIESEBROECK

Econometrics

Center for Economic Studies

Discussions Paper Series (DPS) 12.01

http://www.econ.kuleuven.be/ces/discussionpapers/default.htm

January 2012

DISCUSSION PAPER 


\title{
The Relationship between Market Structure and Innovation in Industry Equilibrium: A Case Study of the Global Automobile Industry*
}

\author{
Aamir Rafique Hashmi ${ }^{\dagger}$ \\ and \\ Johannes Van Biesebroeck ${ }^{\ddagger}$
}

January 9, 2012

\begin{abstract}
We first estimate a dynamic game for the global automobile industry and then compute a Markov Perfect equilibrium to study the equilibrium relationship between market structure and innovation. The key state variable in the model is the efficiency level of each firm and the market structure is characterized by the vector of efficiency levels across all firms. Efficiency is estimated to be stochastically increasing in the dynamic control - innovation - which is proxied by patenting behavior. Equilibrium innovation is a function of all state variables in the industry and the cost of $R \& D$ which includes a privately observed cost shock. We find that it exhibits the following patterns: 1) innovation by the industry leader is decreasing in the efficiency of other firms; 2) innovation is decreasing in the efficiency dispersion; 3) innovation is more concentrated that efficiency; 4) innovation is declining in the number of active firms; 5) the innovation gap between the leader and other firms increases with competition.

Keywords: Competition; Innovation; Dynamic game; Schumpeter
\end{abstract}

JEL Codes: C73; L13; L62; O31

\footnotetext{
${ }^{*}$ We thank participants at various conferences and at seminars at the University of Toronto, National University of Singapore, Victoria University, London School of Economics, and Tilburg University for their comments. We also thank Bart Van Looy and Xiaoyan Song for help with patent data. Financial support from AUTO21, CFI, and SSHRC is greatly appreciated. This is a substantially modified and revised version of an earlier paper that circulated under the title 'Market Structure and Innovation: A Dynamic Analysis of the Global Automobile Industry'.

${ }^{\dagger}$ Department of Economics, National University of Singapore. E-mail: aamir@nus.edu.sg

${ }^{\ddagger}$ Center for Economic Studies, KU Leuven \& CEPR. E-mail: jo.vanbiesebroeck@econ.kuleuven.be
} 


\section{Introduction}

Schumpeter (1942) advanced the controversial argument that monopoly is more conducive to innovation than highly competitive markets. An extensive literature sprung up investigating the effects of market structure on innovative activity, but it has proven difficult to identify robust empirical results. Cohen and Levin (1989) highlight several methodological difficulties that have plagued empirical work. The absence of a monotone relationship and the endogeneity of market structure are two of the most important problems.

A number of theoretical studies have demonstrated that the competition-innovation relationship is monotonic only under restrictive conditions (Gilbert 2006). One reason for this is the opposing impact of the 'efficiency' and 'replacement' effects. The former leads to lower innovation incentives in more competitive situations where aggregate industry profits are lower. The latter leads to lower innovation incentives for a monopolist that has existing profits at stake. Aghion et al. (2005) demonstrate in an explicit model of firm optimizing behavior that the relationship between competition and innovation should have a nonlinear 'inverted-U' pattern. They confirm with data for U.K. firms that stronger competition is associated with higher innovation if competition is low, but that the relationship is inverted when competition is already high.

A second problem for empirical work is the endogeneity of market structure, in particular reverse causality from innovation to market structure. Vives (2008) shows that robust patterns in a set of empirically relevant cases remain sensitive to the assumption of an exogenous market structure versus endogenous entry. The issue has been ignored in much of the empirical literature, although a few studies have exploited quasi-natural experiments where market structure changed exogenously. Carlin, Schaffer, and Seabright (2004) exploit the sudden introduction of competition after the communist model is abandoned in transition countries. Aghion et al. (2005) instrument the change in competition with policy variables associated with the integration of the U.K. economy into the European market.

A host of other factors make it difficult to identify a stable empirical relationship between innovation and market structure. It matters greatly how innovation is exactly introduced in the model. Opposite effects have been demonstrated for product versus process innovations (Boone 2000a), for discrete innovations that do or do not make an existing technology obsolete (Gilbert 2006), and for cases with or without complementarities between different innovation decisions (Kretschmer, Miravete, and Pernias 2009). Furthermore, it is difficult to identify the relationship 
from cross-sectoral variation because profit opportunities and innovation costs vary as well. Market structure variables often turn insignificant if many controls are included (Gilbert 2006). Blundell, Griffith, and Reenen (1999) rely on within-sector comparisons instead, but firm heterogeneity still makes it difficult to identify a stable relationship between innovation and a firm's competitive position (Boone 2000b).

All of the above factors are problematic for reduced form studies that regress a measure of innovation on a measure of competition or market structure. Coefficient estimates will be sensitive to functional form assumptions and to the controls included. In contrast, we propose to study the relationship in an explicit dynamic model of strategic decision making where the absence of robust monotone effects is not a problem, an approach urged by Cohen and Levin (1989), Gilbert (2006), and Sutton (2008). Instead of looking for a relationship that holds similarly everywhere, we can focus on local effects or investigate which control variables are crucial. Opposing effects of market structure on innovation, and vice versa, can be isolated once the primitives of the model are estimated.

We have chosen to estimate the model for the global automotive industry which is highly innovative, both in terms of $R \& D$ expenditure and patents granted. Many firms have experienced pronounced changes in their competitive position over the study period, 1982-2004, which provides identifying power to estimate the structural parameters. The more globalized operations of some initial regional firms have made the global market structure more symmetric with a diminished role for fringe firms and for the very largest firms.

In our model, each firm produces a differentiated product that is characterized by the firm's product quality or, interpreted alternatively, the firm's efficiency level. A firm's market share is determined by its price and its relative efficiency. The price is chosen strategically in each period, taking all efficiencies as given. A firm can stochastically increase its efficiency by investing in $R \& D$, which is a strategic and forward looking decision. A firm takes the actions of its rivals and their possible future states into account.

A few other papers study the interrelation between innovation and market structure in a dynamic model of strategic interaction. Goettler and Gordon (2009) study the microprocessor industry and explicitly incorporate the durable nature of the good by making demand and price setting dynamic as well. They study the impact of market structure on innovation by a counterfactual analysis of monopoly innovation, relying on the primitives estimated from the actual AMD-Intel duopoly. Their finding that as a monopoly Intel would innovate more depends crucially on the durable nature of the good. Upgrades are necessary to stimulate demand and they 
only happen if consumers value quality highly and are relatively price insensitive.

$\mathrm{Xu}(2008)$ analyzes innovation decisions in the Korean electric motor industry. In addition to the cost of $\mathrm{R} \& \mathrm{D}$, he also estimates $\mathrm{R} \& \mathrm{D}$ spillovers, adjustment costs of physical investment, and the distribution of plant scrap value. As he uses the oblivious equilibrium concept of Weintraub, Benkard, and Roy (2008), there is no strategic interaction between plants in the innovation decision. Plants only optimize relative to a stable industry state. ${ }^{1}$ Finally, Siebert and Zulehner (2010) study the reverse question of ours, i.e. how innovation affects market structure. In their study of the DRAM industry, they estimate the evolution of sunk entry costs as the innovation intensity and market demand increase over time. Through their effect on entry and exit, these costs determine equilibrium market structure.

We differ from these other studies in a number of ways. First, we model a continuous control variable, innovation, rather than the zero-one decision in the more common discrete dynamic games. It leads us to the two-step estimation strategy of Bajari, Benkard, and Levin (2007), which does not require to solve for the equilibrium. This estimator has only been used in a few other empirical applications. ${ }^{2}$

Second, we are the first to estimate a model of dynamic industry equilibrium for the automobile industry, which has been a popular proving ground for static models in industrial organization. Hence, we can study the innovation-market structure relationship using functional form assumptions that are well understood.

Third, once all parameters are estimated, we calculate the equilibrium innovation policy, a mapping from all possible market structures a firm might encounter. This allows us to study how innovation incentives within a single industry, holding primitives and parameters constant, vary over the possible states the industry might visit. While the primitives of the model will lead to a particular stochastic steady state, exogenous shocks such as globalization or mergers might lead to many different industry states with possibly very different levels of innovation. With the optimal dynamic policy vector in hand, it is straightforward to conduct a causal analysis of market structure on innovation.

\footnotetext{
${ }^{1} \mathrm{Aw}$ et al. (2011) also study innovation dynamics, but focus on international trade as providing an incentive for innovation. Their dynamic parameters are those that characterize the sunk cost distribution for export and R\&D activities.

${ }^{2}$ Examples are: Ryan (2011), who studies the effect of environmental regulation on the cement industry, and Ellickson and Misra (2008) who study supermarket pricing. Ching (2010) modified the estimator, simultaneously estimating the demand and policy functions, to study demand dynamics in prescription drugs after patent expiry. Jenkins et al. (2004) also modified the estimator, allowing the dynamic parameters to enter nonlinearly, to estimate network effects in the market for internet browsers.
} 
The rest of the paper is organized as follows. In Section 2, we provide background information on the global automotive industry and the data we use. In Section 3 we introduce the static and dynamic aspects of the model as well as the Markov Perfect equilibrium concept. The two-step estimation methodology and the estimation results are discussed in Section 4, followed by a sensitivity analysis. In Section 5, we use the estimated model to analyze the equilibrium interaction between innovation and market structure. We conclude in Section 6.

\section{Background on the industry and the data}

\subsection{Innovation}

The automotive industry is well-suited to investigate the interaction between innovation and market structure in a strategic context. Demand estimates - see for example Berry, Levinsohn, and Pakes (1995) and Goldberg (1995) -indicate large markups over marginal costs, consistent with the view that fixed costs are important in this industry. Innovation is an important source of product differentiation as firms' competitive position is improved through higher product quality, greater reliability, and the introduction of new product features. In addition, the industry is the poster child for the importance of productivity-enhancing process innovations (Van Biesebroeck 2003).

Producing automobiles is a highly research-intensive activity. In 2003, more than $13 \%$ of all R\&D in the OECD was by firms in ISIC industry 34 'Motor Vehicles', more than in any other industry. In 2006 the industry was in third place. Statistics in Table 1 illustrate the importance of automotive $R \& D$ in the five most innovative economies. Except for the U.S. where it is fourth, the industry is first or second in terms of R\&D spending in each country. The top 13 firms in the auto industry spent more than 55 billion dollars on R\&D in 2005.

The industry is also a heavyweight on the output side of the innovation process. In the last 25 years, the same 13 firms were awarded more than 50,000 patents by the U.S. patent office. ${ }^{3}$ We measure the innovative activities of firms by the number of patents they apply for in each calendar year. ${ }^{4}$ We use patents applied for instead of

\footnotetext{
${ }^{3} 5 \%$ of all patents filed in the European patent office (by E.U. applicants) are in the narrow IPC category B60 "Vehicles in general", which is only one of 127 categories and contains only a subset of motor vehicle related innovations; the corresponding fraction at the U.S. patent office is $3 \%$.

${ }^{4}$ Patents are a widely used measure of innovation output. In his survey on use of patents as a measure of technological progress, Griliches (1990) concludes: "In spite of all the difficulties, patents statistics remain a unique resource for the analysis of the process of technical change." [p. 1701]
} 
Table 1: R\&D expenditure by industry in selected countries (2006, in PPP $\$$ b)

\begin{tabular}{lrrrrr}
\hline \hline Industry (ISIC Rev. 3) & USA & Japan & Germany & Korea & France \\
\hline Chemicals (24) & 46.3 & 16.4 & 8.2 & 2.1 & 5.0 \\
Radio, TV, telecom. equipment (32) & 31.2 & 12.2 & 4.1 & 13.3 & 2.8 \\
Motor vehicles (34) & 16.6 & 17.9 & 14.4 & 4.2 & 4.6 \\
Medical, precision, optical instr. (33) & 22.4 & 4.6 & 3.5 & 0.4 & 1.6 \\
Computing and related machinery (30) & 7.4 & 14.1 & 0.6 & 0.4 & 0.2 \\
\hline \hline
\end{tabular}

Note: Includes all sectors in the top three by R\&D expenditure in any of the five countries. Industries are sorted by total $R \& D$ expenditure across the five countries.

Source: OECD ANBERD database, edition 2009 (online).

patents granted to minimize time delay problems. We use patents instead of $R \& D$ expenditure, because only in recent years is the $\mathrm{R} \& \mathrm{D}$ data available for all firms in consolidated global accounts. Moreover, these firms also spend vast amounts on engineering and design, which in some countries might be partially included in R\&D expenditures.

The information about patents comes from the PATSTAT database. Since firms often file for patents through various subsidiaries, we searched the database for all records containing the core of the parent firm's name and manually verified the results. The number of applications for each firm-year observation to the U.S. and European patent offices are combined as follows: $x_{j t}=\max \left(x_{j t}^{U S}, \lambda x_{j t}^{E U}\right) . \lambda$ is the relative weight given to more expensive and more demanding European patents. It is computed by taking the ratio of U.S. to European patents observed for four large firms (Daimler, Ford, Honda and Toyota) that have significant sales and production in both regions. We compute this weight to be 2.36. It implies that for automotive firms one European patent represents the same amount of innovation as 2.36 American patents.

\subsection{Market structure}

The automotive industry is concentrated worldwide, making it likely that firms will take actions of competitors into account when deciding on their own innovative activities. We measure sales by the number of vehicles sold worldwide by each firm and its affiliates. ${ }^{5}$ This information is obtained from Ward's Info Bank, the Ward's Automotive Yearbooks, and the online data center of Automotive News for the most recent years. Market shares in Table 2 are computed as a fraction of total worldwide

\footnotetext{
${ }^{5}$ We do not distinguish between minority share holdings and outright control. E.g. Mazda is counted as part of the Ford group, even though Ford Motor Co. never held more than $33.4 \%$ of Mazda's shares.
} 
Table 2: Market shares in the initial and final year of the sample

\begin{tabular}{lccccc}
\hline \hline & \multicolumn{2}{c}{1982} & & \multicolumn{2}{c}{2004} \\
\cline { 2 - 3 } \cline { 5 - 6 } & $\begin{array}{c}\text { Sales } \\
\text { (in '000) }\end{array}$ & $\begin{array}{c}\text { Market } \\
\text { Share }\end{array}$ & & $\begin{array}{c}\text { Sales } \\
\text { (in '000) }\end{array}$ & $\begin{array}{c}\text { Market } \\
\text { Share }\end{array}$ \\
\hline Chrysler & 1,408 & $(3.8 \%)$ & & {$[$ merged with Daimler] } \\
Daimler & 701 & $(1.9 \%)$ & & 4,719 & $(8.1 \%)$ \\
Ford & 5,415 & $(14.5 \%)$ & & 7,590 & $(13.1 \%)$ \\
GM & 6,463 & $(17.3 \%)$ & & 8,990 & $(15.5 \%)$ \\
Honda & 1,015 & $(2.7 \%)$ & & 3,194 & $(5.5 \%)$ \\
Hyundai & 91 & $(0.2 \%)$ & & 3,328 & $(5.7 \%)$ \\
Nissan & 2,604 & $(7.0 \%)$ & & {$[$ partnered } & with Renault] \\
PSA & 1,644 & $(4.4 \%)$ & & 3,375 & $(5.8 \%)$ \\
Renault & 2,026 & $(5.4 \%)$ & & 5,785 & $(9.9 \%)$ \\
Toyota & 3,282 & $(8.8 \%)$ & & 6,708 & $(11.5 \%)$ \\
VW & 2,200 & $(5.9 \%)$ & & 5,079 & $(8.7 \%)$ \\
\hline Sample total & 26,850 & $(71.9 \%)$ & & 48,768 & $(83.9 \%)$ \\
Global total & 37,337 & & 58,147 & \\
\hline \hline
\end{tabular}

Source: Ward's Automotive and Automotive News.

new vehicle sales.

We only focus on the largest global firms, which are responsible for the bulk of innovation, as we explicitly study strategic interaction. Our sample includes the eleven largest firms which together sold $72 \%$ of all new vehicles worldwide in 1982. After two big tie-ups, a merger between Daimler and Chrysler in 1998 and a close partnership between Nissan and Renault in 1999, the number of firms was reduced to nine. By 2004, the firms in the sample controlled $84 \%$ of the global market. The remaining new vehicle sales are by smaller firms and we assume they do not innovate strategically. ${ }^{6}$

A couple of patterns in Table 2 stand out. Only the largest three firms - GM, Ford, and the union of Nissan-Renault-lost market share over the sample period. The industry became more symmetric over time as some firms that initially operating mostly in their home region globalized. The market share gains of the other firms were not only at the expense of the top firms. They took an additional $12 \%$ of market share away from the peripheral firms, partly as a result of takeovers. The fortunes of the firms that gained market share also varied. While PSA increased its share by a third, from $4.4 \%$ to $5.8 \%$, Honda more than doubled it from $2.7 \%$ to $5.5 \%$, and Hyundai increased it by a factor of more than 25, from $0.2 \%$ to $5.7 \%$.

\footnotetext{
${ }^{6}$ In the model below, the difference between global sales and total sample sales will be accounted for by an outside good.
} 
Table 3: Summary statistics

\begin{tabular}{lrrcc}
\hline \hline Variable & Mean & S.D. & 10th pctile & 90th pctile \\
\hline Patents & 311 & 268 & 56 & 769 \\
Sales (in thousands) & 3,653 & 2,439 & 900 & 7,866 \\
Log price (reference firm =0) & -0.03 & 0.13 & -0.19 & 0.19 \\
Efficiency (reference firm $=0)$ & -1.53 & 0.97 & -2.35 & 0.48 \\
\hline \hline
\end{tabular}

Note: The number of observations for each variable is 240 .

Again because of our focus on strategic interaction in the global automotive industry, we abstract from the various vehicle models sold by each firm. Instead, we assume a 'composite' model and construct a price for it by estimating a hedonic price regression. Pooling all available models in a market over the sample period, we regress the list price in logarithm on a rich set of vehicle characteristics - see Goldberg and Verboven (2001) for an example. We include a full set of firm-year interaction dummies and the coefficients on these capture the relative price for each firm in each year.

This price is relative to the average price charged by a set of peripheral firms, which are included in the difference between sample and total market in Table 2. It measures what consumers are willing to pay for a particular firm's vehicle compared to a peripheral vehicle with the same characteristics. We estimate this hedonic regression separately for the U.S. passenger vehicle market, and jointly for five E.U. countries. $^{7}$ The (sales) weighted average of a firm's price in the two markets is its global price, normalized to zero for the peripheral firms in each year.

The last piece of information we will need to estimate our dynamic model is the state variable, firm efficiency or product quality. We do not use independent information for this, but use the residual from a transformed demand equation, the $\xi_{j}$ term in Berry (1994). This measure includes everything that affects a firm's market share except the observed vehicle characteristics and prices. It is observed by all firms in the industry, but not by the econometrician. Most importantly for our purpose, we hypothesize that its evolution is influenced by innovation.

Summary statistics for the four variables that enter the model are reported in Table 3. Recall that the sample contains eleven firms over 23 years (1982-2004). All firms in the sample are very innovative, applying for an average of 311 patents per year. The standard deviation of 268 suggests that there is a lot of variation in innovative activities. Average annual sales in the sample is 3.7 million vehicles,

\footnotetext{
${ }^{7}$ We have updated the data sets in Petrin (2002) and Goldberg and Verboven (2001) to 2004 using information from JATO Dynamics.
} 


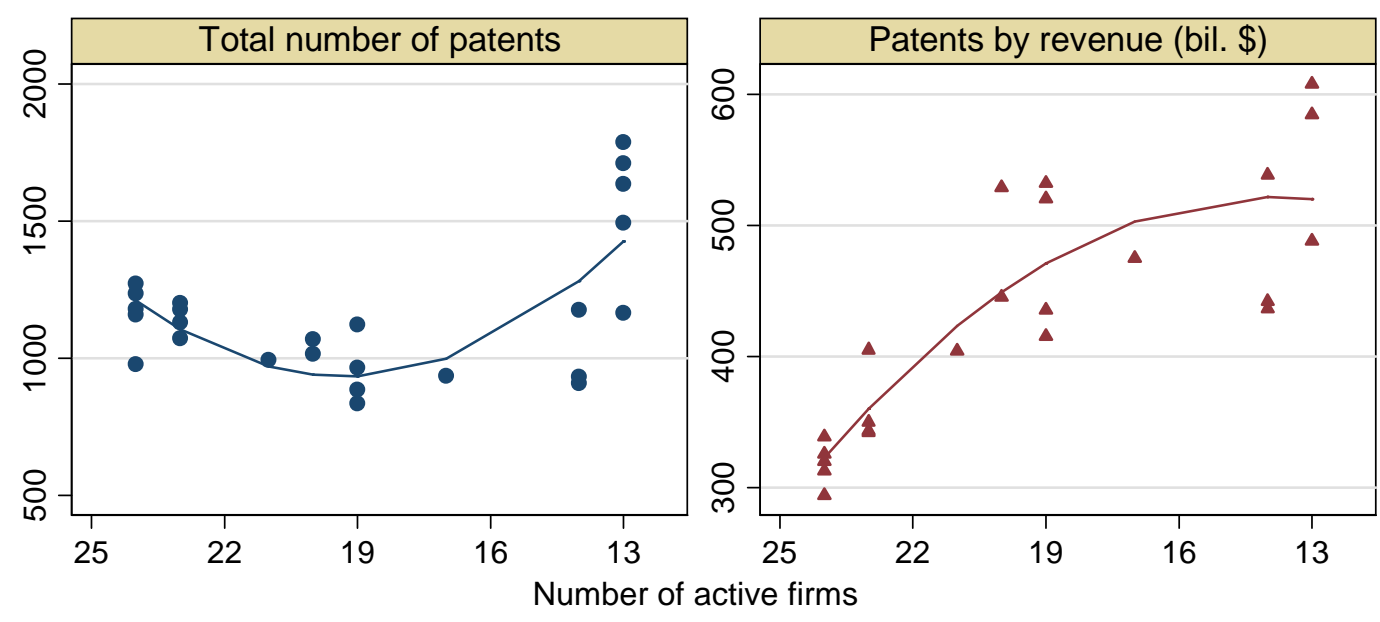

Figure 1: Aggregate relationship between innovation and market structure

with a standard deviation of 2.4 million. The log price averages around zero $(-0.03$ to be specific) and 10th to 90th percentiles range from -0.19 to 0.19 . The average efficiency level is -1.53 , with a standard deviation of 0.97 .

\section{$2.3 \quad$ A first look at the relationship}

To illustrate the observed relationship between market structure and innovation in the raw data, we plot in Figure 1 two measures of innovation at the industry level against the total number of active firms. Note that we use information on all 24 internationally active firms in this section and not only on the 11 largest. ${ }^{8}$ Because the overall rate of patenting in the economy has increased notably over time, especially after 1984 (Hall 2004), we purge the innovation variables on the vertical axis from a cubic time trend and plot the residual. The patterns rely solely on time series variation as the global industry has gradually become more concentrated - we have reversed the scale of the $\mathrm{X}$-variable to coincide with the progression of time.

Both measures, the total number of patents and the ratio of patents to revenue, indicate that even after controlling for the time trend innovation was highest in the later years when fewer firms were active. In the graph on the left this is driven entirely by the data for the last couple of years when patenting increased markedly. The fitted relationship shows a U-shaped pattern, but the data points indicate that this was not a gradual evolution. There was a downward trend in patenting over most of the period as the industry consolidated from 24 to 13 independent firms. This trend reversed suddenly and strongly once merger activity stopped.

Normalizing the total number of patents by revenue suggests a rather different

\footnotetext{
${ }^{8}$ Most of these smaller firms were at some point absorbed by one of the larger firms.
} 


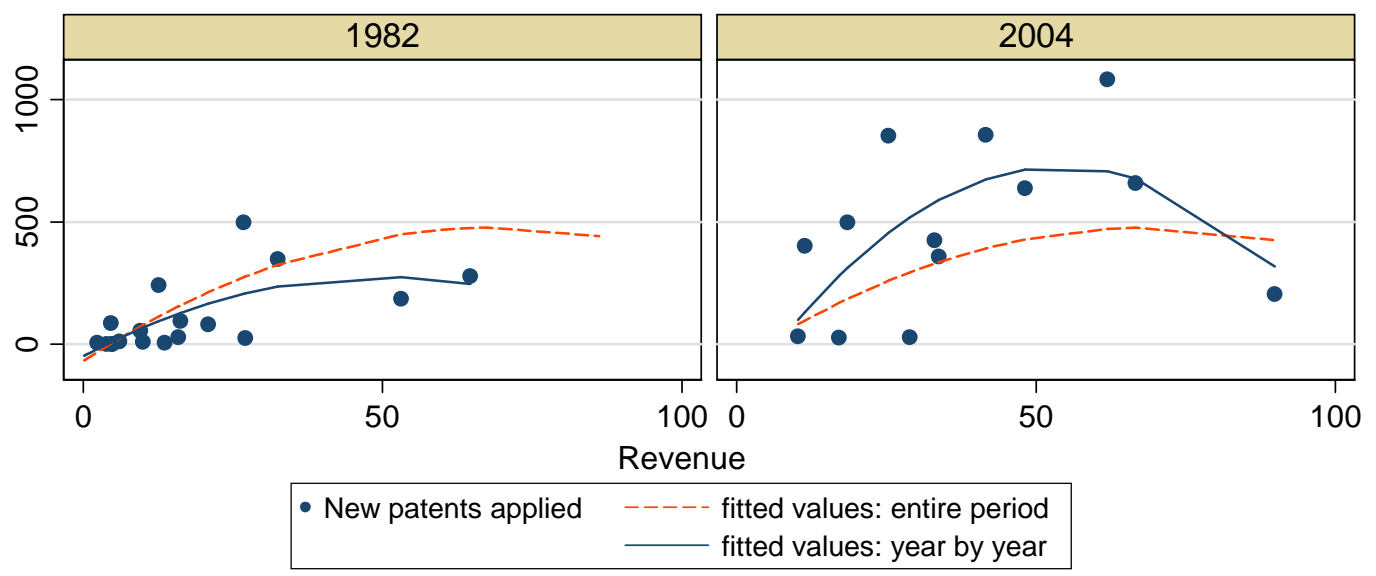

Figure 2: Firm-level relationship between innovation and market structure

pattern. The relationship is now clearly positive: the patent-to-sales ratio is increasing in the number of firms. In later years, the relationship breaks down as the patenting ratio stops its increase. Both patterns are consistent with opposing 'efficiency' and 'replacement' effects, but which effect dominates depends on the innovation measure used.

The aggregate relationship hides important underlying variation. Even conditioning on the competitive state of the industry in a given year, there are large differences across firms in the number of patents they apply for. The relationship between firm size, measured by revenue, and the number of patents is depicted in Figure 2 for the initial and last years. In both years the relationship is inverted-U shaped (solid lines) and the same holds for the fitted relationship over the entire sample period (dashed lines). On average the smallest firms patent the least, while the most innovative firms are those in the middle of the size distribution.

This pattern is even more pronounced for patents by revenue as innovation measure. It is consistent with the evidence for U.K. manufacturing firms in Aghion et al. (2005). In order to gauge whether the mechanisms leading up to this are also consistent with their interpretation, we need a model of firm behavior and industry competition.

\section{The Model}

We write down a simple model of industry equilibrium with forward-looking innovation decisions. Firms decide on their innovation effort based on the current market structure and a (private) cost of innovation. At the same time, they realize that their individual decisions collectively and stochastically determine the evolution 
of the market structure. Our modeling strategy follows Ericson and Pakes (1995) except for the absence of entry and exit which have not been important in this industry.

Time is discrete. There are $n$ firms in the industry, each producing a single differentiated product. Firms are heterogenous with respect to their relative efficiency level, $\xi_{j} \in \Xi$. At the beginning of each period, firms observe the full state vector for the industry, their own cost of innovation, and they decide on price and investment in R\&D. While price-setting can be thought of as the equilibrium outcome of a static Bertrand-Nash game, the investment decisions are the outcome of a dynamic game of incomplete information.

\subsection{The Static Problem}

Prices influence current profits, but have no effect on the future. They are chosen conditioning on the industry state vector and in equilibrium no firm should be willing to deviate unilaterally. The outcome from the static problem is a mapping from all possible industry states to a vector of profit levels for each firm under optimally chosen equilibrium prices.

The demand system is derived from a discrete choice model of individual consumer behavior, following Berry, Levinsohn, and Pakes (1995) and many others studying the automobile industry. Vehicles differ in quality, $\xi$, which is observable to all firms and consumers, but not to the econometrician. There are $m$ consumers in the market and each buys one vehicle. The utility for consumer $i$ from buying vehicle $j$ depends on its quality, its price and the consumer's idiosyncratic preferences as follows

$$
u_{i j}=\theta_{p} \log \left(p_{j}\right)+\xi_{j}+\varepsilon_{i j}, \quad i=1, \ldots, m, \quad j=1, \ldots, n
$$

$\theta_{p}$ is the price elasticity of demand. ${ }^{9}$ The price of vehicle $j$ incorporates an adjustment for a set of vehicle characteristics as described in the data section. In addition to the $n$ firms that innovate and price strategically and are the focus of our study, there are a number of peripheral firms. We normalize the consumer's utility from buying a vehicle from a peripheral firm, the outside good, to zero.

If we assume that the idiosyncratic utility $\varepsilon_{i j}$ is i.i.d. extreme value distributed,

\footnotetext{
${ }^{9}$ We do not use a random coefficients model because our main focus is on innovation and not on substitution patterns or on consumer heterogeneity beyond what is implied by $\varepsilon_{i j}$.
} 
we obtain the following expected market share for firm $j:^{10}$

$$
\sigma_{j}\left(\xi_{j}, \xi_{-j}, p_{j}, p_{-j}\right)=\frac{\exp \left(\theta_{p} \log \left(p_{j}\right)+\xi_{j}\right)}{1+\sum_{k=1}^{n} \exp \left(\theta_{p} \log \left(p_{k}\right)+\xi_{k}\right)},
$$

where $p_{-j}$ is the price vector of all other firms than $j$ in the industry. The expected demand is simply $m \sigma_{j}(\cdot)$. The demand that each firm faces depends on the full price vector for all firms, directly through the denominator of (2) and indirectly through its own price which, in equilibrium, is a function of its rivals' prices.

Each firm chooses its price taking the industry state and rival prices as given. The profit maximization problem of firm $j$ is

$$
\pi_{j}\left(\xi_{j}, \xi_{-j}, p_{-j}, m \mid \theta_{p}, \theta_{c}\right)=\max _{p_{j}}\left\{p_{j}-\mu_{j}\left(\xi_{j} \mid \theta_{c}\right)\right\} m \sigma_{j}\left(\xi_{j}, \xi_{-j}, p_{j}, p_{-j} \mid \theta_{p}\right) .
$$

$\mu_{j}$ is the marginal cost of firm $j$ and it might vary with the relative efficiency level. This allows for higher vehicle quality translating in higher costs, but also for costreducing process innovations. $\theta_{c}$ are the parameters in the marginal cost function.

The first order condition for firm $j$, after some simplification, is

$$
\left\{p_{j}-\mu_{j}(\cdot)\right\}\left\{1-\sigma_{j}(\cdot)\right\} \theta_{p}+p_{j}=0
$$

With $n$ active firms, we have to solve $n$ such first order conditions simultaneously to obtain the equilibrium price vector $\left\{p_{j}^{*}, p_{-j}^{*}\right\}$. Existence and uniqueness of equilibrium in this context is proved by Caplin and Nalebuff (1991). The equilibrium profits are then given directly by

$$
\pi_{j}^{*}\left(\xi_{j}, \xi_{-j}, m \mid \theta_{p}, \theta_{c}\right)=\left\{p_{j}^{*}-\mu_{j}\left(\xi_{j} \mid \theta_{c}\right)\right\} m \sigma_{j}\left(\xi_{j}, \xi_{-j}, p_{j}^{*}, p_{-j}^{*} \mid \theta_{p}\right)
$$

Once the functional forms and parameter values of the demand and cost functions are known, the vector of $\pi^{*}$ values for all firms can be calculated for any state of the industry using equation (4).

\subsection{The Dynamic Problem}

The optimal innovation decision is a dynamic problem that generates an evolution for the firm's state variable. We now have to be more specific on the domain $\Xi$ for $\xi$. It is defined by specifying lower and upper bounds and discretizing the intermediate range of possible values in steps of $\Delta_{\xi}$. As a result, $\Xi=\left\{\xi_{\min }, \xi_{\min }+\Delta_{\xi}, \cdots, \xi_{\max }-\right.$ $\left.\Delta_{\xi}, \xi_{\max }\right\}$. Recall that $\xi_{j}$ is the relative efficiency of firm $j$, defined by normalizing

\footnotetext{
${ }^{10}$ Anderson, de Palma, and Thisse (1992, p. 136) illustrate how the CES demand system can equivalently be motivated using the representative consumer framework.
} 
the absolute efficiency level by the average efficiency of a set of peripheral firms. The benefit of this formulation is that $\xi_{j}$ is naturally bounded.

Firms also differ in their cost of $R \& D$, which is the sum of a common part that is a function of $\mathrm{R} \& \mathrm{D}$ expenditure $x_{j}$ and a private shock $\nu_{j} \in \mathbb{R}$ that is i.i.d. across firms and over time and only observed by firm $j$. The state vector for firm $j$ is then given by $\left\{\xi_{1}, \cdots, \xi_{j}, \cdots, \xi_{n}, \nu_{j}\right\}$, which we write in short as $\mathbf{s}_{j}=\left\{\xi_{j}, \xi_{-j}, \nu_{j}\right\} .{ }^{11}$ These random shocks perform the same function as the choice-specific state variables in Rust (1987) or Gowrisankaran et al. (2009). They make sure that each investment choice has positive probability.

Investment in $\mathrm{R} \& \mathrm{D}$ is a strategic and dynamic decision, chosen each period based on the expected value of future profit streams. The problem is recursive and can be described by the following Bellman equation

$$
\begin{aligned}
V_{j}\left(\xi_{j}, \xi_{-j}, \nu_{j} \mid \theta\right)=\max _{x_{j} \in \mathbb{R}^{+}}\left\{\pi_{j}\left(\xi_{j}, \xi_{-j} \mid \theta_{p}, \theta_{c}\right)-c\left(x_{j}, \nu_{j} \mid \theta_{x}\right)\right. \\
\left.+\beta E V_{j}\left(\xi_{j}^{\prime}, \xi_{-j}^{\prime}, \nu_{j}^{\prime} \mid \xi_{j}, \xi_{-j}, x_{j}, \theta\right)\right\}
\end{aligned}
$$

where $\beta$ is the discount factor and $c(\cdot)$ the cost of $\mathrm{R} \& \mathrm{D}$ that depends on the dynamic parameters in $\theta_{x}$. $\theta$ combines all parameters of the model. The variables with a prime denote the next period values. The expectation is with respect to the evolution of the entire state vector $\mathbf{s}_{j}^{\prime}$ and firm $j$ conditions this on $x_{j}, \xi_{j}$, and $\xi_{-j}$, but not $\nu_{j}$ as it is assumed to be i.i.d. over time.

The expected value can be written explicitly as

$$
\begin{aligned}
& E V_{j}\left(\xi_{j}^{\prime}, \xi_{-j}^{\prime}, \nu_{j}^{\prime} \mid \xi_{j}, \xi_{-j}, x_{j}, \theta\right)= \\
& \quad \sum_{\nu_{j}^{\prime}} \sum_{\xi_{-j}^{\prime}} \sum_{\xi_{j}^{\prime}} V_{j}\left(\xi_{j}^{\prime}, \xi_{-j}^{\prime}, \nu_{j}^{\prime} \mid \theta\right) P_{\xi}\left(\xi_{j}^{\prime} \mid \xi_{j}, x_{j}, \theta_{t}\right) P_{\xi}\left(\xi_{-j}^{\prime} \mid \xi_{-j}, E\left(x_{-j}\right), \theta_{t}\right) P_{\nu}\left(\nu_{j}^{\prime}\right)
\end{aligned}
$$

where $E\left(x_{-j}\right)=\sum_{\nu_{-j}} x_{-j} P_{\nu}\left(\nu_{-j}\right)$. We need to take the expectation over the rivals' investments $x_{-j}$ as they determine the evolution of the industry state, but they depend on cost shocks $\nu_{-j}$ that firm $j$ does not observe. $\theta_{t}$ are the parameters in the state transition function.

The evolution of $\nu_{j}$ is straightforward. We assume it to be i.i.d. over time and across firms and to follow a normal distribution with a mean of zero and standard deviation $\sigma_{\nu}$, which is one of the dynamic parameters in the vector $\theta_{x}$.

The evolution of $\xi_{j}$, denoted by $P_{\xi}\left(\xi^{\prime} \mid \xi, x, \theta_{t}\right)$, depends on the firm's choice of $x_{j}$ and is assumed to depend also on the distance of the firm's relative efficiency to the

\footnotetext{
${ }^{11}$ The market size $m$ is another state variable that is the same for all firms. To keep the size of the state space manageable, we assume that it is constant over time.
} 
frontier $\xi_{\max } \cdot{ }^{12}$

We follow Ericson and Pakes (1995) and assume that next period's efficiency level can only take three possible values if current efficiency is $\xi_{j}:\left(\xi_{j}+\Delta_{\xi}\right)$, $\xi_{j}$, or $\left(\xi_{j}-\Delta_{\xi}\right)$. On the discretized domain, efficiency can increase or decrease by one step or stay the same. The probability distribution over these possible future states is given by the triplet $\left\{p^{U}, p^{S}, p^{D}\right\}$, which are defined as

$$
\begin{aligned}
p^{U} & =\operatorname{Pr}\left(\xi_{j}^{\prime}=\xi_{j}+\Delta_{\xi} \mid \xi_{j}\right) \\
p^{S} & =\operatorname{Pr}\left(\xi_{j}^{\prime}=\xi_{j} \mid \xi_{j}\right) \\
p^{D} & =\operatorname{Pr}\left(\xi_{j}^{\prime}=\xi_{j}-\Delta_{\xi} \mid \xi_{j}\right) .
\end{aligned}
$$

The functional forms for the transition probabilities will incorporate that the firm cannot move up anymore when it is at $\xi_{\max }$ or down when it is at $\xi_{\min }$.

The solution to (5) is a strategy profile $x_{j}=\chi_{j}\left(\xi_{j}, \xi_{-j}, \nu_{j} \mid \chi_{-j}\right)$. The Markov Perfect Equilibrium (MPE) of the game is a strategy profile $\chi_{j}^{*}$ that solves (5) given that all rivals follow the same equilibrium strategy as firm $j$. It is given by $\chi_{j}^{*}\left(\xi_{j}, \xi_{-j}, \nu_{j} \mid \chi_{-j}^{*}\right)$, which we denote for short as $\mathbf{X}^{*}(\mathbf{s})$.

In the estimation of the dynamic parameters $\theta_{x}$ we exploit the properties of the equilibrium strategy profile. The estimation approach is described in the next section, where we also introduce the functional form assumptions for the marginal costs and the transition probabilities.

\section{Estimation Methodology and Results}

We need to estimate parameters from four functions: demand $\left(\theta_{p}\right)$, marginal cost $\left(\theta_{c}\right)$, state transitions $\left(\theta_{t}\right)$, and the cost of $\mathrm{R} \& \mathrm{D}\left(\theta_{x}\right)$. The first two sets of parameters can be estimated from the specification of the static problem and the third set is merely a parametric description of the observed process in the data. The major challenge is to estimate the dynamic parameters in the cost of R\&D function. With nine to eleven firms in the industry, the brute force method of computing the Markov Perfect Equilibrium (MPE) and matching predicted to observed innovation decisions is computationally infeasible.

\footnotetext{
${ }^{12}$ This assumption is supported by the data. The following fixed-effects regression characterizes changes in efficiency,

$$
\Delta \xi_{j t}=\underset{(0.10)}{0.28}+\underset{(0.09)}{0.13} x_{j t-1}-\underset{(0.03)}{0.13} \xi_{j t-1}+\hat{\gamma}_{j} .
$$

Innovation has a positive effect on the change in efficiency, but a higher level of initial efficiency makes it harder to improve further.
} 
Recently, a number of alternative approaches have been developed that do not require the calculation of the equilibrium of the game. As observed investment decisions are equilibrium outcomes, they are used directly to characterize the policy function and the state transition function (non)parametrically. ${ }^{13}$

We adopt the two-step estimator of Bajari, Benkard, and Levin (2007) as it is directly applicable to our situation with a continuous choice variable. ${ }^{14}$ In the first step, state transition probabilities and the equilibrium policy functions are combined with the estimates of the period profit function to obtain numerical estimates of the value function by forward-simulation. In the second step, the dynamic parameters are chosen to minimize the deviations from equilibrium conditions, which occur when the value function is higher under policies that differ from the optimal policies.

We present benchmark estimates and some sensitivity checks immediately following the discussion of the estimation methodology for the different elements of the model.

\subsection{Step 1}

\subsubsection{Demand and Cost Parameters}

The demand side in our model is static and we can follow Berry (1994) to write the log market share of firm $j$ relative to a base firm as ${ }^{15}$

$$
\log \left[\sigma_{j}(\cdot) / \sigma_{0}(\cdot)\right]=\theta_{p} \log \left[p_{j} / p_{0}\right]+\left[\xi_{j}-\xi_{0}\right] .
$$

This can be estimated using the observed market shares and price data. The relative efficiency levels of all firms are then simply the residuals from the demand equation. Consistent estimation requires that we account for the endogeneity of prices as firms use unobserved vehicle quality in their pricing decisions. In particular, we expect the price coefficient to be biased upward if we estimate with ordinary least squares.

The usual instruments in this context are the product characteristics of rival firms, see for example Berry et al. (1995). In our case, we do not have any characteristics in the demand equation, as they have already been accounted for in the construction of the price series. However, lagged patent activity by rival firms should be correlated with the quality of their current products and thus be correlated with a competitor

\footnotetext{
${ }^{13}$ While this approach is widely used in single agent dynamic problems since Hotz and Miller (1993), in a dynamic game context the assumption is less innocuous due to the possibility of multiple equilibria, see Doraszelski and Pakes (2007).

${ }^{14}$ Alternative approaches that avoid computing the MPE at each iteration include Aguirregabiria and Mira (2007) and Pakes, Ostrovsky, and Berry (2007).

${ }^{15}$ All estimators in Step 1 pool data across all years; time subscripts are omitted.
} 
firm's price. We also include firm-fixed effects in the regression, which already absorb much of the endogeneity as unobserved product quality varies a lot more between firms than over time. The fixed effects are added again to calculate the $\xi_{j}$ series. Finally, we perform a sensitivity check for the estimation of the dynamic parameters by selecting a higher and lower price elasticity parameter than the one we estimate.

If marginal costs are assumed constant, the demand function can be estimate alone. If marginal cost varies with a firm's efficiency level, it is estimated jointly with the first order condition for price setting to recover both sets of coefficients. We use the following specification for the marginal cost function, where the coefficient on the quadratic term can be fixed to zero or estimated freely:

$$
\mu_{j} / \mu_{0}=\theta_{c 0}+\theta_{c 1} \tilde{\xi}_{j}+\theta_{c 2} \tilde{\xi}_{j}^{2}+\varepsilon_{j}^{m c}
$$

with $\tilde{\xi}_{j}=\exp \left(\xi_{j}-\xi_{0}\right)$.

The estimates for the three different specifications of marginal cost together with the corresponding price elasticity estimates are reported in Table 4. Price enters negatively and significantly in each case. Given the $\log (p)$ in the indirect utility function, we are estimating a CES demand model and the coefficient on price directly gives the price elasticity of demand. Joint estimation of the demand with the first order condition guarantees an elasticity above unity, but we find this holds even when demand is estimated separately. Weak instruments or controlling imperfectly for the product characteristics in the hedonic price regression would lead to an upwardly biased price coefficient. Both issues do not appear to be problematic.

The estimates range between -3.9 and -2.5 , which tends to be lower in absolute value than the average elasticities that in studies using model-level data. This is consistent with the more aggregate product definition as the residual demand for a firm should be less elastic than for an individual model. The implied price-marginal cost markups are correspondingly lower. Again, this is reasonable because at the firm level more costs will be variable than at the model level.

The relationship between marginal cost and the unobserved quality term is negative, in both the linear and quadratic cases. ${ }^{16}$ It is counterintuitive that firms seem to be able to produce higher quality vehicles at lower costs. It is therefore better not to think of $\xi$ as just product quality, but any unobservable that makes the firm achieve high sales. It is not surprising that factors that make a firm succeed in the marketplace are correlated with factors that make it produce efficiently.

\footnotetext{
${ }^{16}$ The same holds if we specify the logarithm rather than the level of marginal cost as the linear function in equation (7).
} 
Table 4: Parameter estimates for demand and marginal cost functions

\begin{tabular}{|c|c|c|c|}
\hline & $\begin{array}{c}\text { Constant MC } \\
(1)\end{array}$ & $\begin{array}{c}\text { Linear MC } \\
(2)\end{array}$ & $\begin{array}{c}\text { Quadratic MC } \\
(3)\end{array}$ \\
\hline & \multicolumn{3}{|c|}{ Demand parameters } \\
\hline \multirow[t]{3}{*}{ Price } & -3.925 & -2.950 & -2.512 \\
\hline & $(1.605)^{*}$ & $(0.431)^{* *}$ & $(0.413)^{* *}$ \\
\hline & \multicolumn{3}{|c|}{ Marginal cost parameters } \\
\hline \multirow[t]{2}{*}{ Constant term } & 0.059 & -0.042 & -0.225 \\
\hline & $(-)$ & $(0.012)^{* *}$ & $(0.059)^{* *}$ \\
\hline \multirow[t]{2}{*}{ Unobserved quality $(\tilde{\xi})$} & & -0.108 & -0.396 \\
\hline & & $(0.024)^{* *}$ & $(0.116)^{* *}$ \\
\hline \multirow[t]{2}{*}{ Unobserved quality-squared } & & & -0.068 \\
\hline & & & $(0.033)^{*}$ \\
\hline
\end{tabular}

Notes: Includes firm-fixed effects in demand and instruments price with lagged patenting of rivals. In columns (2) and (3), demand and the first order condition are estimated jointly. **,${ }^{*}$ indicate significance at the $1 \%$ and $5 \%$ level.

\subsubsection{Policy function and state transition}

In addition to the demand and cost parameters, we need the values of future state variables to calculate future profits. Using the observed patenting decisions, we characterize the empirical innovation policy as a function of the state variables.

Ideally, the control variable $x$ should be modeled as a completely flexible function of a firm's own state and the full vector of its rivals' states. Given the data limitations, we use the following specification:

$$
x_{j t}=\alpha_{1} \bar{\xi}_{t}+\alpha_{2} \sigma_{\xi t}+\alpha_{3} \xi_{t}^{\max }+\alpha_{4} \xi_{j t}+\alpha_{5} \xi_{j t}^{2}+\gamma_{t}^{D C}+\gamma_{t}^{N R}+e_{j t},
$$

which includes the mean, maximum, and standard deviation of the $\xi$ distribution as well as the firm's own efficiency and efficiency squared. We also include two dummies for the post-merger periods for Daimler-Chrysler and Nissan-Renault. $e_{j t}$ is an approximation error between the innovation that the true policy function would generate and our prediction. We do not report the full set of coefficients for the policy function as they have no direct interpretation. Note that the policy function is re-estimated for robustness checks with different marginal cost specifications.

Innovation stochastically determines the evolution of the state variable according to the three probabilities in equation (6). Let $p \in[0,1]$ be the probability that a firm's efficiency moves up by one step and $d \in[0,1]$ the probability that it depreciates by one step. Assuming that $p$ and $d$ are independent,${ }^{17}$ the probabilities of moving

\footnotetext{
${ }^{17}$ This assumption is consistent with the data. If we add an interaction term between $x_{j t-1}$ and
} 
up, staying put, or moving down are

$$
\begin{aligned}
p^{U} & =p(1-d) \\
p^{S} & =p d+(1-p)(1-d) \\
p^{D} & =(1-p) d,
\end{aligned}
$$

and we use the following parameterizations for $p$ and $d$ :

$$
\begin{aligned}
p & =1-\exp \left(-\theta_{t 1}-\theta_{t 2} x\right) \\
d & =\exp \left(-\theta_{t 3} \frac{\xi_{\max }-\xi}{\xi_{\max }-\xi_{\min }}\right) .
\end{aligned}
$$

This specification has several attractive properties. First, if $\theta_{t 2}>0$ patenting increase the probability that efficiency increases. Second, if innovation goes to infinity, efficiency increases almost surely. Third, even if a firm does not innovate there is some positive probability that its efficiency improves. Fourth, if $\theta_{t 3}>0$, the probability that efficiency depreciates is inversely related to the distance from the frontier.

Together these probabilities fully define the transition function $P_{\xi}\left(\xi^{\prime} \mid \xi, x\right)$. They also imply that when a firm is at maximum efficiency, the probability of a further increases is zero because $d=1$. At the other extreme, when the firm is at the minimum level of efficiency, it does not hold automatically that $p^{D}=0$ and we need to enforce this. If $\xi=\xi_{\min }$, we assume that $p^{D}=0$ and adjust $p^{S}$ to equal $1-p^{U}$.

We now outline how we estimate the three parameters in the $\theta_{t}$ vector. Because the state variable $\xi$ is continuous in the data, we first need to discretize it. The size of the state space has an important impact on the computational burden in step 2 and we use a relatively coarse discretization. We limit $\xi$ to lie in the -3.0 to 0.2 interval and use a distance between consecutive values of 0.4 . It implies that $\xi$ can take nine different values.

In Figure 3, we plot the continuous $\xi$ values that are recovered as residuals from the demand estimation in the top panel. The discretized series is shown in the bottom panel. The correlation between the two is 0.943 , suggesting that the approximation works reasonably well. Moreover, Figure 3 shows that there is sufficient variation in the discretized $\xi$ series over time that we can hope to capture interesting dynamics.

Following Rust (1987), we estimate the state transition parameters by maximum likelihood. Recall that a change in $\xi$ can take only three possible values: $\left\{-\Delta_{\xi}, 0, \Delta_{\xi}\right\}$. To construct the log-likelihood function, we simply take the corresponding probability from $\left\{p^{U}, p^{S}, p^{D}\right\}$ and evaluate them using the $\xi$ and $x$ values $\xi_{j t-1}$ in the regression in footnote 12 , its coefficient is statistically insignificant. 

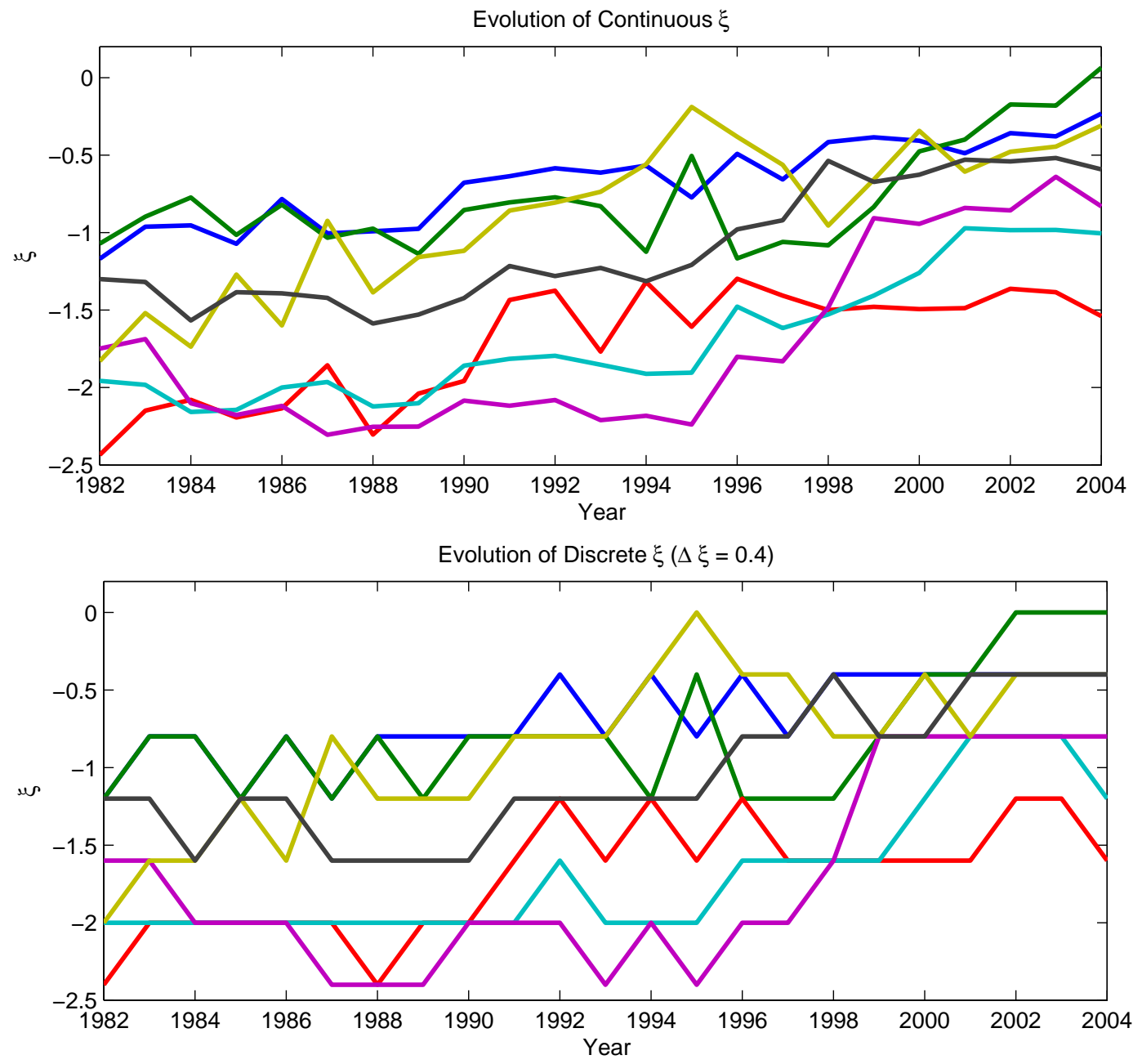

Figure 3: Evolution of efficiency for selected firms

Note: The top panel shows the estimated (continuous) values for $\xi$ and the bottom panel the discretized efficiency levels used in the model.

for each observation. The objective function is then the sum of the logarithms of the relevant probabilities over all observations in the sample.

The parameter estimates for the three specifications for marginal costs are in Table 5. We faced two problems. First, due to the coarse discretization of $\xi$, some of the standard errors are extremely high. With a finer discretization this problem largely disappears, with t-statistics above 1.5 even for $\theta_{t 3}$. We use the current point estimates to reduce the computational burden in the next step.

Second, the parameter estimate for $\theta_{t 2}$, which captures the impact of innovation on the probability that efficiency increases, is negative in the third specification, although it is estimated very imprecisely. It would imply that innovation lowers the probability of improving efficiency. This problem does not appear when using 
Table 5: Transition probability parameters estimates

\begin{tabular}{cccc}
\hline \hline & Constant MC & Linear MC & Quadratic MC \\
& $(1)$ & $(2)$ & $(3)$ \\
\hline$\theta_{t 1}$ & 1.745 & 2.469 & 3.636 \\
$($ constant term in $p)$ & $(0.37)^{* *}$ & $(0.48)^{* *}$ & $(0.41)^{* *}$ \\
$\theta_{t 2}$ & 0.564 & 0.323 & -0.626 \\
$($ coefficient on $x$ in $p)$ & $(1.11)$ & $(1.30)$ & $(1.01)$ \\
$\theta_{t 3}$ & 0.656 & 0.448 & -1.105 \\
$($ coefficient in $d)$ & $(4.10)$ & $(4.99)$ & $(0.63)^{*}$ \\
\hline \hline
\end{tabular}

Notes: Maximum likelihood estimates. ${ }^{* *},{ }^{*}$ indicate significance at the $1 \%$ and $10 \%$ level.

the continuous $\xi$ values in this case, i.e. running a regression similar to the one in footnote 12. As we need to discretize the state variable for the estimation of dynamic parameters, we will focus on the first two specifications.

\subsubsection{Computation of the Value Function}

Combining all the building blocks with a set of initial values for the structural parameter vector $\theta_{x}$, we can calculate a numerical estimate of the value function for any industry state $\mathbf{s}=\left\{\xi_{1}, \cdots, \xi_{n}, \nu_{1}, \cdots, \nu_{n}\right\}$. We do this by forward simulating profit realizations.

We start from an initial industry state $\mathbf{s}_{0}$ : the observed values of $\xi_{t}$ for a given year supplemented by a set of random draws on the cost shock $\nu$. The system of first-order conditions (3) together with the estimated demand and cost parameters allow the calculation of the equilibrium price vector. The estimated policy function directly provides optimal innovation decisions for all firms. Substituting both in the net profit function vector, equation (4) minus the cost of innovation, gives a vector of values for all active firms: $\pi_{0}\left(\mathbf{s}_{0}\right)-c\left(\mathbf{x}_{0}, \mathbf{s}_{0} \mid \theta_{x}^{0}\right)$.

Next, we use the estimated transition probabilities to find the industry state for the next period $\mathbf{s}_{1}$. For each $\left(x_{j}, \xi_{j}\right), j \in[1, \cdots, n]$ we compute the three probabilities in (6) and then draw a realization of $\xi_{j 1}$ from the appropriate distribution. This updates the industry state to $\mathbf{s}_{1}$. Following the same steps as above we can compute the expected net profit in period 1 for each firm, which is discounted back to period 0 .

This process is repeated $T$ periods, until $\beta^{T}$ gets arbitrarily close to zero. We have set the discount factor to 0.9 and $T$ to 150 periods $\left(\beta^{150}=3.70 E-06\right)$. The 
value functions are then simply the present discounted values of these profit streams:

$$
V\left(\mathbf{s}_{0} \mid \theta_{x}^{0}\right)=E\left[\sum_{t=0}^{T} \beta^{t}\left[\pi_{t}\left(\mathbf{s}_{t}\right)-c\left(\mathbf{x}_{t}, \mathbf{s}_{t} \mid \theta_{x}^{0}\right)\right]\right],
$$

where the expectation is over future states. We perform these forward simulations 10, 000 times using different draws for the $\nu$ shocks and the realizations of the state transitions. The average over all simulations is the numerical estimate of $V\left(\mathbf{s}_{0} \mid \theta_{x}^{0}\right)$ for starting state $\mathbf{s}_{0}$. We repeat this for all observed industry states by taking each as the starting state for a separate set of simulations.

\section{$4.2 \quad$ Step 2}

We are finally ready to estimate the dynamic parameters of the model using the minimum distance estimator proposed by Bajari, Benkard, and Levin (2007). Let $\chi_{j}^{*}\left(\xi_{j}, \xi_{-j}, \nu_{j} \mid \chi_{-j}^{*}\right)$ be the Markov perfect equilibrium policy profile for firm $j$. For this to be the equilibrium strategy, the value function following this strategy must be higher than for any alternative strategy $\chi_{j}^{\prime}$ :

$$
V_{j}\left(\xi_{j}, \xi_{-j}, \nu_{j} \mid \chi_{j}^{*}, \chi_{-j}^{*}, \theta_{x}\right) \geq V_{j}\left(\xi_{j}, \xi_{-j}, \nu_{j} \mid \chi_{j}^{\prime}, \chi_{-j}^{*}, \theta_{x}\right)
$$

Note that only firm $j$ deviates from the MPE strategy, while its rivals still play their Nash strategies. Equation (10) will hold at the true value of the parameter vector $\theta_{x}^{*}$

Using the forward simulation procedure as described above, we can calculate the value function for both for the optimal and for a number of alternative policy profiles. The difference $d\left(\xi_{j}, \xi_{-j}, \nu_{j} \mid \chi_{j}^{\prime}, \theta_{x}\right)=V_{j}\left(\xi_{j}, \xi_{-j}, \nu_{j} \mid \chi_{j}^{*}, \chi_{-j}^{*}\right)-V_{j}\left(\xi_{j}, \xi_{-j}, \nu_{j} \mid \chi_{j}^{\prime}, \chi_{-j}^{*}\right)$ enters the objective function of the minimum distance estimator only if it is negative as this implies a violation of equilibrium condition (10). For a given vector of $\theta_{x}$, we calculate these differences for all firms $j$, industry states $\mathbf{s}$, and alternative policies $\chi^{\prime} . \hat{\theta}_{x}$ is then chosen to minimize the sum of the squared negative terms to minimize the violations of the MPE, i.e.

$$
\hat{\theta}_{x}^{*}=\arg \min \sum_{j, \mathbf{s}, \chi^{\prime}}\left[\min \left\{d\left(\xi_{j}, \xi_{-j}, \nu_{j} \mid \chi_{j}^{\prime}, \theta_{x}\right), 0\right\}\right]^{2} .
$$

The specific alternative policies that we use are the following deviations from the equilibrium Nash policy: $\chi_{j}^{\prime}=(1+\iota) \chi_{j}^{*}$, where $\iota$ takes the following four values: [0.90 0.951 .051 .10$]$. And finally, we parameterize the cost of R\&D function as:

$$
c\left(x_{j}, \nu_{j} \mid \theta_{x}\right)=\left(\theta_{x 1}+\theta_{x 2} x_{j}+\theta_{x 3} \tilde{\nu}_{j}\right) x_{j},
$$


Table 6: Dynamic parameter estimates

\begin{tabular}{cccc}
\hline \hline & \multicolumn{2}{c}{ Constant MC } & Linear MC \\
& $(1)$ & $(2)$ & $(3)$ \\
\hline$\theta_{x 1}$ & 71 & 144 & 83 \\
$($ coefficient on $x)$ & $(165)$ & $(99)$ & $(-)$ \\
$\theta_{x 2}$ & 0.066 & & \\
$\left(\right.$ coefficient on $\left.x^{2}\right)$ & $(0.138)$ & & \\
$\theta_{x 3}$ & 490 & 441 & 169 \\
$($ coefficient on $\nu)$ & $(220)^{*}$ & $(226)^{*}$ & $(-)$ \\
\hline \hline
\end{tabular}

Notes: Minimum distance estimation, see text. Standard errors are bootstrapped. ${ }^{* *},{ }^{*}$ indicate significance at the $1 \%$ and $5 \%$ level.

where $\tilde{\nu}_{j}$ is a standard normal variable and $\theta_{x 3} \tilde{\nu}_{j}=\sigma_{\nu} \tilde{\nu}_{j}=\nu_{j}$.

The estimates for three different specifications of the model are reported in Table 6. They are based on a normalization of the marginal cost to 1 . The standard errors are bootstrapped, re-estimating all intermediate parameters as well. ${ }^{18}$

In the first column, we use the specification with constant marginal production cost and a quadratic function for the cost of innovation. To put the magnitudes in perspective, the expected $\mathrm{R} \& \mathrm{D}$ expenditure to apply for 700 patents, which is approximately the mean in the last few years of the sample, is estimated to be $85,334\left(=71 x+0.066 x^{2}\right)$ times the marginal cost. If we assume that the marginal cost of producing a vehicle is $\$ 15,000$, it amounts to a total innovation outlay of $\$ 1.28$ billion or $\$ 1.78$ million per patent. The convexity of the cost of $\mathrm{R} \& \mathrm{D}$ function implies that the cost per patent rises to $\$ 2.33$ million for firms at the high end of the observed patenting range. Moreover, each firm received each period a positive or negative shock to the cost of R\&D and the high estimated standard error indicates we really need this exogenous source of variation to rationalize observed patenting rates.

In the second column, we restrict the R\&D function to be linear in the number of patents. The estimate of 144 implies a cost per patent of $\$ 2.16$ million. Because the standard error for $\hat{\theta}_{1}$ is much lower in the restricted model, we use this estimate in the remainder of the paper. The coefficient is still not estimated very precisely, but the p-value for a one-sided test against a zero cost is only $0.073 .{ }^{19}$

\footnotetext{
${ }^{18}$ We draw without replacement 20 subsamples of 12 years each, from the 23 total years in the sample. For each subsample, we re-estimate demand, policy, and state transition parameters, and then use forward simulations and the minimum distance estimator to estimate the dynamic parameters.

${ }^{19}$ Increasing the number of subsamples raises the precision somewhat, but is computationally very demanding in our model with up to 11 active firms.
} 
We have investigated the sensitivity of the estimates in column (2) to the price elasticity of demand, which is a key parameter in the model. It determines not only how high the price-cost margins and thus profits are, but also how consumers trade off lower prices and higher quality. Both are key considerations in the firms' innovation decision. In the benchmark case with constant marginal cost, the price elasticity was estimated at -3.92 . We re-estimate the dynamic parameters when the elasticity is set to one half and to double the estimated value.

As the price elasticity rises from -1.96 , over -3.92 , to -7.85 , the $\hat{\theta}_{1}$ estimate falls from 261, to 144 , and 114. The intuition is the following. When demand is less elastic, markups are higher and so are profits from increased sales. In addition, consumers value a high vehicle quality relatively more than a low price. As a result, the incentives to innovate are raised and to rationalize the observed number of patents in the data we need a higher cost of R\&D.

At the same time, the $\hat{\theta}_{3}$ estimate for the standard deviation of the shock to innovation falls from 1059, to 441, and 19. This is the result from an asymmetric effect of the cost shocks. As we impose that the cost of $R \& D$ can never be negative, a higher standard deviation mainly has an effect on the positive side, i.e. to discourage innovation. Several firms in the data are observed to innovate less than we would predict based on the model primitives and the shock rationalizes their behavior. When the price elasticity is very high, the incentives to innovate in the model are reduced and we can fit the patenting activity without requiring large variations in the cost of innovation.

The results reported in the third column of Table 6 allow the marginal production cost to vary with firm efficiency. Recall that we found marginal costs to be declining in efficiency in Table 4, but we nevertheless find lower estimates for both $\hat{\theta}_{1}$ and $\hat{\theta}_{3}$, at 83 and 169. It is counterintuitive that the model comes up with a lower cost of innovation to match observed rates of patenting when patents have the additional benefit of lowering production costs. The explanation comes from the differences in state-transition estimates. The lower estimates for $\hat{\theta}_{t 2}$ in the second column of Table 5 implies that innovation has less of a positive effect on the probability that efficiency improves in this case. The lower estimate for $\hat{\theta}_{t 3}$ implies slower depreciation of efficiency, further reducing the incentive to innovate. These effects outweigh the boost in incentives coming from the production costs. 


\section{$5 \quad$ Market Structure and Innovation}

\subsection{Computation of Equilibrium}

Now that we have estimated all the parameters in the model, we can compute just once the Markov perfect equilibrium strategy of a firm for all possible industry states it might find itself in. These strategies will then be used to study the equilibrium dynamics of market structure and innovation. We follow the algorithm of Pakes and McGuire (1994) and provide some of the details in the Appendix.

The notorious computational burden stems mainly from three sources. The size of the state space, the computation of the continuation value, and the number of iterations that the algorithm takes to converge. To limit the size of the state space we use a coarse discretization of $\xi$ as discussed before. We also compute the equilibrium for eight instead of the nine or eleven firms in the sample. We demonstrate below that this equilibrium already contains rich dynamics to inform us on the question of interest. To reduce the burden of computing continuation values in all possible future market structures, we follow Pakes and McGuire (1994) and assume that from each efficiency level today, a firm can only reach three possible values in the next period. With eight firm, this still leaves $6,561\left(=3^{8}\right)$ possible values for the industry state in the next period.

With these steps, it takes about 10 days of CPU time to compute the equilibrium once. It is important to point out that for a dynamic game of this size, multiple equilibria are the rule rather than the exception. We compute just one possible equilibrium out of the potentially many. For the different starting values for $X^{0}$ and $V^{0}$ that we tried, the algorithm always converged to the same equilibrium.

In Figure 4, we assess the in-sample performance of the model. We compare optimal innovation under the equilibrium strategy with the observed innovation for industry states contained in our data set. In Panel (a) of Figure 4 we have sorted all observations on the horizontal axis in ascending order of expected innovation - the thick red line. The three thin lines show the expected innovation if the shock to the cost of $\mathrm{R} \& \mathrm{D}$ is $-\sigma_{\nu}, 0$, and $\sigma_{\nu}$. The circles represent the actual innovation in the data. The figure illustrates that the vast majority of observed innovation decisions are within the range of predictions that a one standard deviation cost shock generates. It is also clear, however, that this range is rather wide. ${ }^{20}$

In Panel (b), we plot the observed innovation on the $x$-axis against the predicted

\footnotetext{
${ }^{20}$ To avoid negative values for the cost of innovation we have set the standard deviation for the private $R \& D$ shock to one tenth of its estimated value throughout.
} 


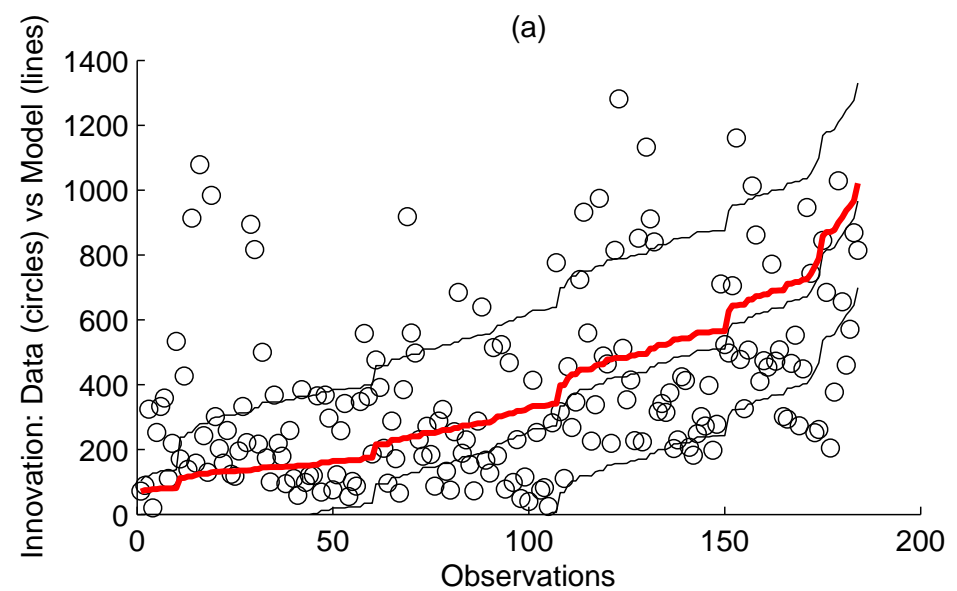

(b)

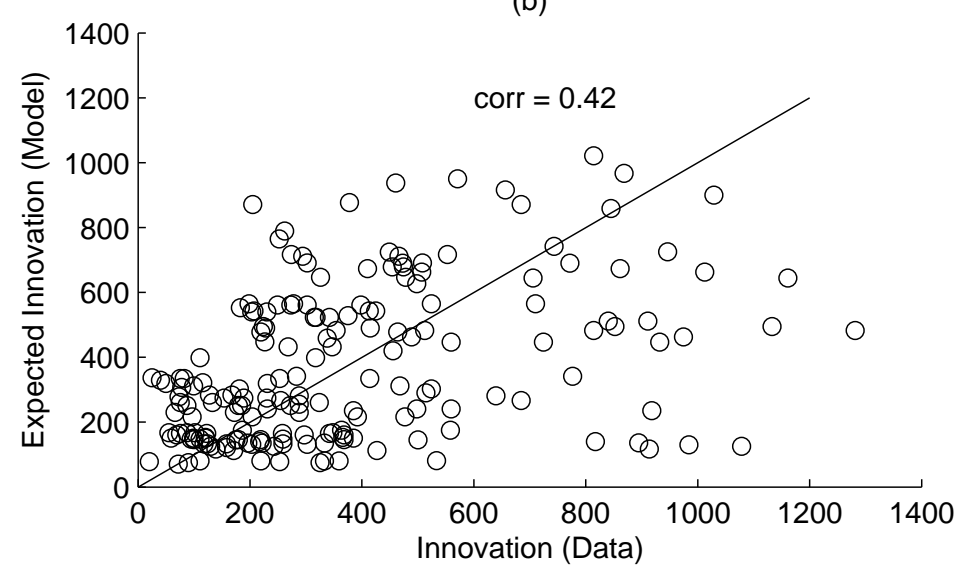

(c)

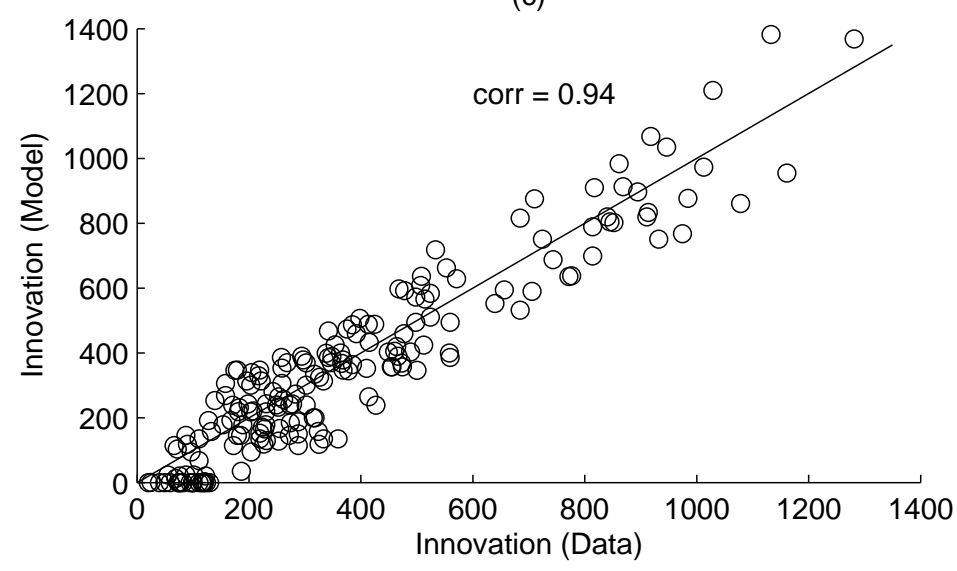

Figure 4: In-sample performance of the model

Notes: (a) The red line shows the expected equilibrium innovation. The three thin lines, starting from the top, show innovation when the shock to the cost of $R \& D$ is $-1,0$ and +1 , respectively. The circles show innovation in the data. (b) The scatter plot of innovation in the data and expected innovation from the model. (c) The scatter plot of innovation in the data and innovation from the model with the appropriate shock to the cost of $R \& D$. 
equilibrium innovation on the $y$-axis. The correlation is 0.42 and the model only does a modest job of predicting the data. This should not be surprising as the estimated importance of the random shock to the cost of $R \& D$ was rather large. We allowed the shock to the cost of $\mathrm{R} \& \mathrm{D}$ to take one of five values: $\left\{-2 \sigma_{\nu},-\sigma_{\nu}, 0, \sigma_{\nu}, 2 \sigma_{\nu}\right\}$. Expected innovation is computed by taking the expectation over the equilibrium innovation for each possible realization of the shock. In Panel (c), we report the equilibrium innovation when we pick for each observation the value of the shock (out of the 5 possible values) that minimizes the difference between actual and equilibrium innovation. The correlation between the actual and equilibrium innovation is now 0.94 , illustrating that the model is capable of rationalizing the data quite well.

In Figure A.1 in the Appendix we further illustrate that the calculated optimal investment policy leads to an evolution of efficiency levels that captures the observed patterns quite well. Starting from the observed industry state in 1982 for the eight largest firms, we simulate the industry forward till 2004 one thousand times using the optimal innovation policy. The average evolution (red lines) track the actual evolutions (black lines) rather well. ${ }^{21}$ The average correlation between the actual and predicted efficiency levels is 0.75 .

\subsection{Equilibrium Relationship between Market Structure and Inno- vation}

We now turn to the main question that motivated the paper: what is the equilibrium relationship between market structure and innovation in the global automobile industry? We illustrate several patterns by graphing optimal innovation using the MPE policy vector against specific variations in market structure.

We use the optimal policies that we calculated for all possible market structures because in the data we only observe a small set of states for the industry. This is illustrated in Figure A.2 in the Appendix, where we forward simulate the model using optimal innovation and random draws on the transition process. The figure shows the average efficiency in the industry for one thousand periods starting from an initial state where all eight firms have $\xi_{j}=-0.5$. We see that there can be quite dramatic endogenous changes. For example, in the 30 periods following $t=380$, the average efficiency level increases from close to -1 to almost -0.1 . There are several such episodes and they imply even more dramatic changes at the firm level. We also see that, despite the sometimes dramatic changes, the industry is in a stochastic steady state.

\footnotetext{
${ }^{21}$ The averaging over different industry realizations has smoothed the predicted evolution.
} 


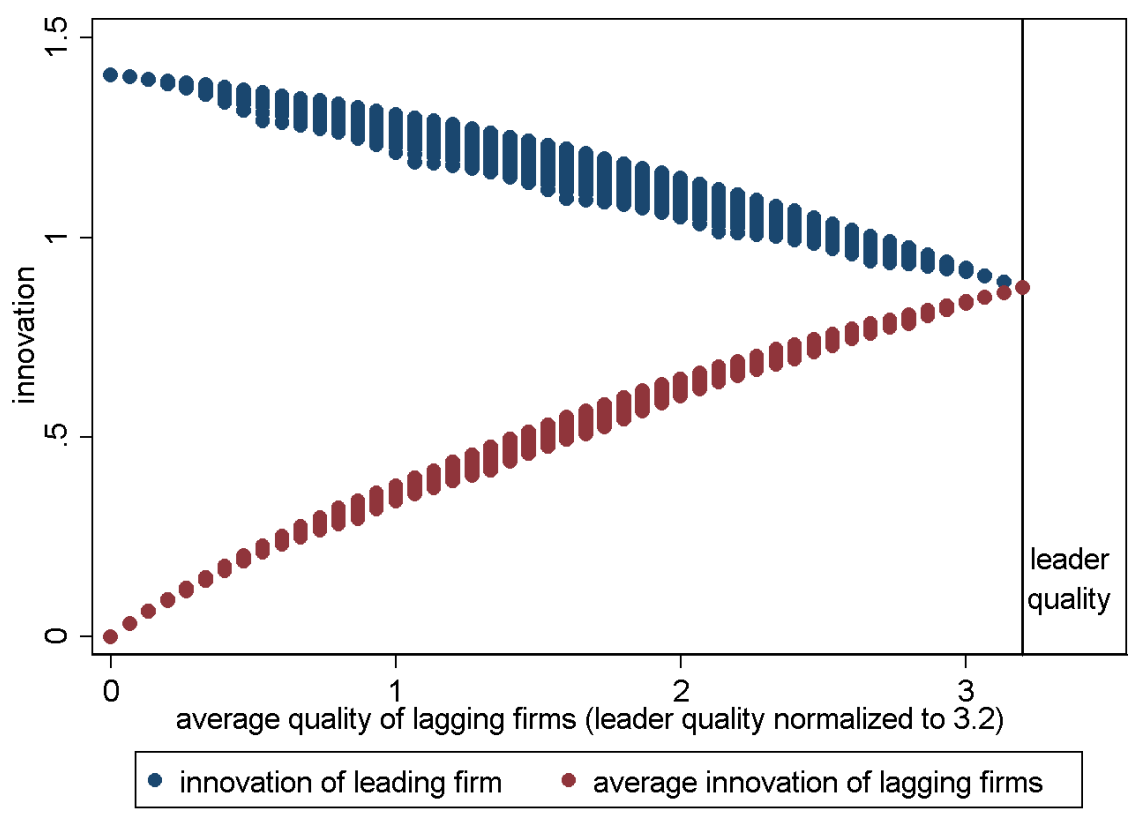

Figure 5: Innovation as a function of the quality gap

Notes: The different markers represent various possible market structures that give the same average quality for lagging firms.

When we use the optimal MPE vector to study the impact of market structure on innovation, we always hold constant the own efficiency level of the firm we study. The model generates a strong positive relationship between a firm's efficiency level and its innovation, which is illustrated in Figure A.3 in the Appendix. In the following three figures, we hold the efficiency of a firm constant and study how its optimal innovation changes when we vary the market structure that the firm operates in.

The first pattern in Figure 5 illustrates that the leading firm innovates most when its advantage over lagging firms is largest. The blue markers at the top show the innovation of the leader in a variety of market structures where its own efficiency is always at the same level. ${ }^{22}$ The red markers show that innovation of lagging firms increases as they catch up to the leader, but this mostly reflects the strong positive correlation between own-efficiency and innovation already alluded to before.

The magnitude of the effect on the leader is very large. Faced with a group of lagging firms that are all at minimum efficiency, the leader innovates $50 \%$ more than when the other firms have almost caught up. Note that this large innovation response shows up even though we keep the leader's own efficiency level fixed throughout. A change in innovation of 0.5 represents applying for 500 fewer patents per year and it is more than half of the additional innovation performed by the average lagging

\footnotetext{
${ }^{22}$ We have normalized the minimum of $\xi$ to zero and chosen a level of 3.2 for the leader.
} 


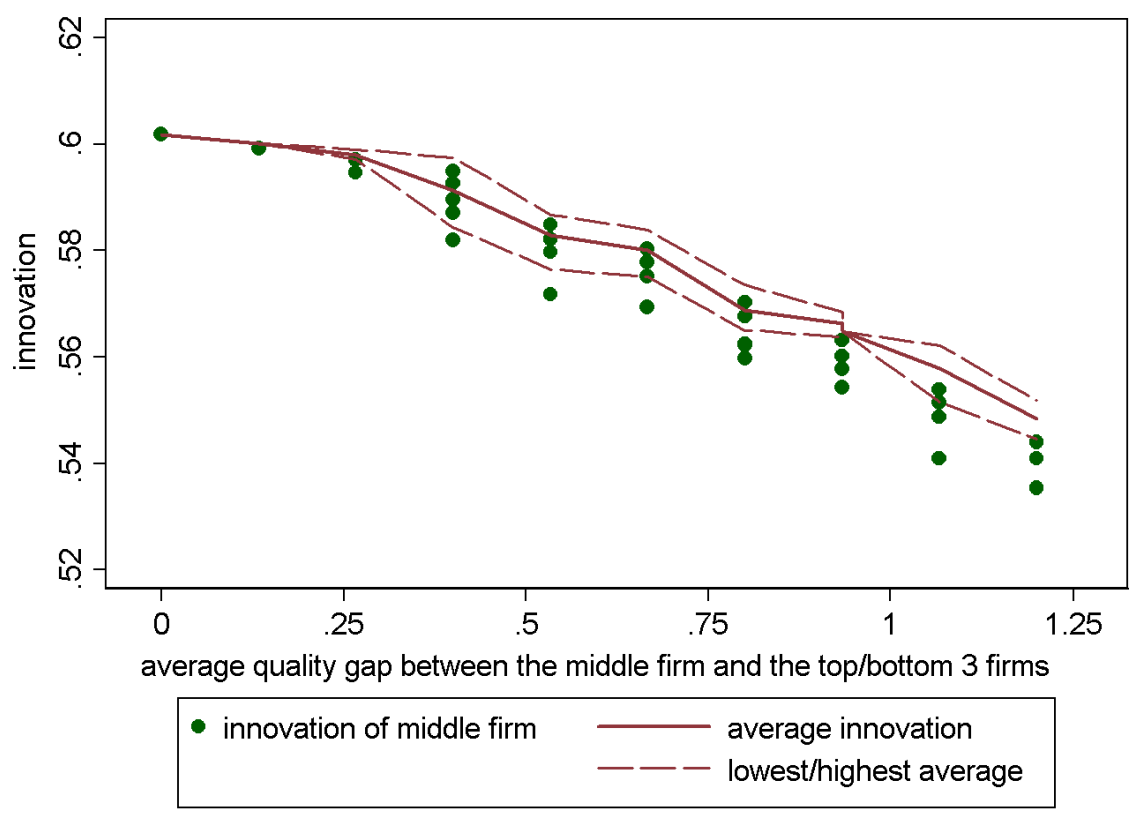

Figure 6: Innovation as a function of mean-preserving quality dispersion

firm as its efficiency level is raised over the full range of the state variable. ${ }^{23}$.

The second pattern in Figure 6 looks at innovation of a firm holding constant not only its own efficiency level and its relative position in the industry, but also the average level of efficiency for the industry as a whole. On the horizontal axis we measure the dispersion of efficiency in the industry, where variation is added in a mean-preserving way. On the vertical axis we indicate innovation of the middle firm (green markers), the average innovation for the industry (solid line) and the lowest and highest industry average innovation across different market structures (dashed lines). ${ }^{24}$

The central pattern in this figure is of declining innovation as efficiency becomes more unequal. The middle firm innovates less when its distance to the industry leaders grows, even though its own advantage over laggards grows by the same amount. Average innovation falls as well, which is the result of a concave relationship between innovation and own efficiency (Figure A.3). As a result, holding total efficiency for the industry constant, total innovation is maximized when the efficiency is divided equally among firms.

\footnotetext{
${ }^{23}$ Figure A.3 in the Appendix shows that the innovation of a group of symmetric firms grows by approximately the same amount, from 0.25 to 0.75 , if their efficiency level is raised over the full range of the state variable

${ }^{24}$ We only show market structures where no firm is at zero efficiency as the sudden drop in innovation at that point would introduce small jumps in the figure.
} 
The previous pattern in Figure 5 works against this trend of declining average innovation with dispersion. Innovation incentives for the leaders get stronger as their advantage grows, but this effect is not strong enough to overcome the effect of concavity. It does show up, however, in a less pronounced decline of the average innovation level compared with the decline for the middle firm.

These same effects also give rise to a positive and more than proportional relationship between concentration in innovation and in efficiency. When the allocation of the state variable is more concentrated, innovation is also more concentrated. The relationship, shown in Figure A.4 in the Appendix, is even steeper than the 45 degree line. A $50 \%$ rise in the Herfindahl index for efficiency can double the Herfindahl index for innovation. At the same time, total innovation for the industry is a declining function of the concentration in efficiency, in line with the dispersion results in Figure 6.

Another interesting question is whether industry leaders innovate more than followers. However, it is difficult to make such a comparison while holding constant own efficiency and total efficiency for the industry. The only way to do this is to make the distribution less dispersed when we consider the leader's innovation, but Figure 6 already demonstrated that this in itself raises innovation. We made a number of comparisons for an industry consisting of just three firms and found innovation to be between $1.1 \%$ and $3.3 \%$ higher for a leader compared to a follower with the same efficiency level, when holding total efficiency in the industry constant as well.

We can make similar comparisons to verify whether a firm at the very bottom innovates more or less than a firm in the middle. Again, the only way to do this while holding own efficiency and total industry efficiency constant is to make the distribution less dispersed for the bottom firm. Across several cases, we find that the bottom firm innovates $0.7 \%$ to $4.1 \%$ more than the middle firm. These results suggest that innovation is higher for firms at the very top or bottom than for firms in the middle, but we cannot rule out entirely that this is the result of efficiency dispersion rather than the firm's own position in the industry.

The above results are all for the specification of the model with constant marginal production costs. The pattern in Figure 5 is similar when we use the model with marginal production costs declining in efficiency. Only the range of innovation over different possible market structures is wider, both for the leader and lagging firms. The pattern in Figure 6 is similar for the middle firm, but the average innovation in the industry is now increasing in dispersion, see Figure A.5 in the Appendix. The reason is that the relationship between own-efficiency and innovation is still increasing, but now has an S-shape rather than being concave. It makes the innovation 


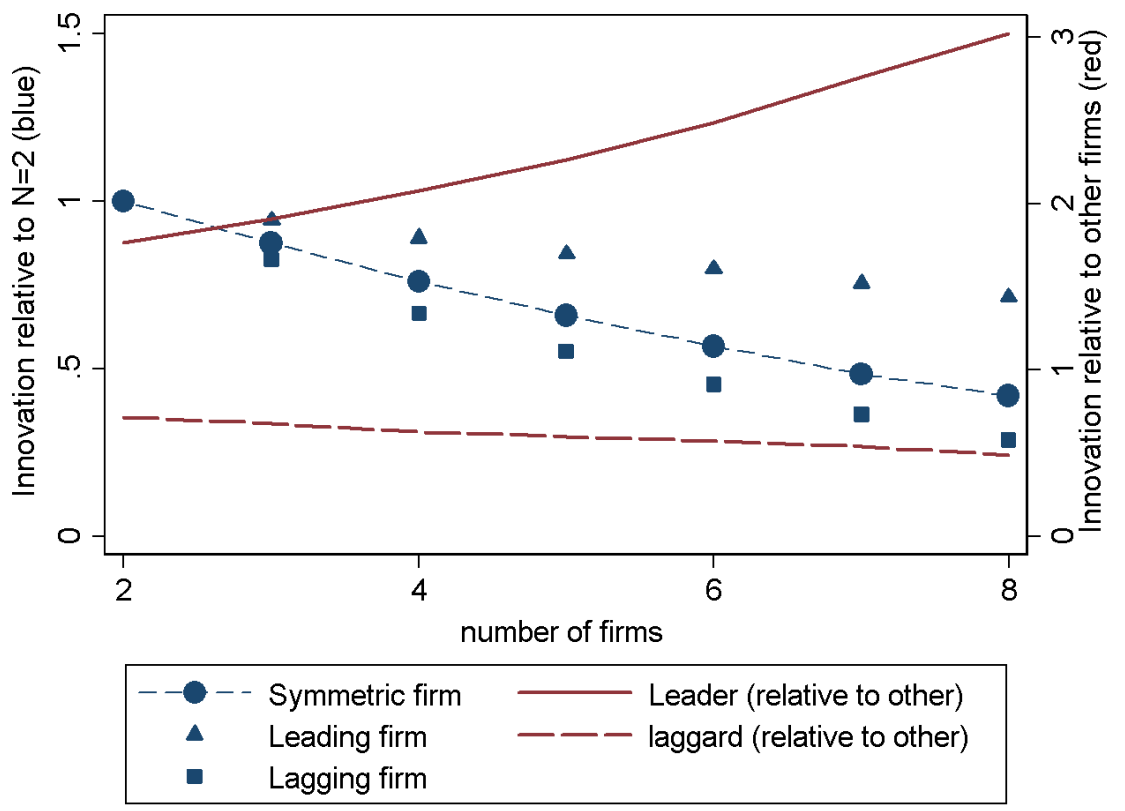

Figure 7: Innovation as a function of the number of firms

boost for the leading firms more important and suggests that in this case aggregate innovation would be much higher if efficiency were highly asymmetric. ${ }^{25}$

The last pattern in Figure 7 illustrates how innovation changes when the number of competitors is exogenously increased. ${ }^{26}$ Again, we hold the relative and absolute position of a firm constant and plot its optimal level of innovation as we add firms to the market. Additional firms are always entered at the mean level of efficiency. The blue circled markers are for a firm that is also at the mean efficiency level, i.e. all firms in the industry are symmetric in this case. The figure shows a monotonically declining rate of innovation with competition, consistent with the efficiency effect. As the number of active firms increases in a market of constant size, profit rates will go down and innovation incentives with them. Firms do take some market share away from the outside good, but it is not enough to compensate for the additional competition. Note that the interpretation here is really the innovation response to an exogenous change in market structure as we always use the optimal MPE innovation policy.

The same pattern of declining innovation with competition holds for leading and lagging firms, but for firms that are ahead of the new entrants the innovation decline

\footnotetext{
${ }^{25}$ The same mechanism also leads to higher average innovation for higher levels of the Herfindahl index in efficiency in this case.

${ }^{26}$ To construct this figure we computed the optimal policy vector for different numbers of active firms.
} 
is much less pronounced. To illustrate this more clearly, we included red lines on the graph that express innovation of an existing leading or lagging firm relative to the innovation of firms at average efficiency, either existing or new entrants. The interpretation of the red lines is that they are the optimal innovation policies of leaders or laggards, relative to the optimal policies of average firms.

For existing industry leaders, their relative rate of innovation increases strongly when additional competitors enter the market. A firm with a competitive advantage will increase its innovation lead over other firms when faced with more competition. While its absolute level of innovation is declining with entry, it declines much less than the innovation of other (average) firms. This pattern is in line with the replacement effect. A firm that is innovating to defend its competitive position, increases the gap with other firms when facing more competition.

\section{Concluding remarks}

We have accomplished two things. First, we estimated all parameters in a structural game-theoretic model of strategic, forward-looking, innovating firms for a particular sector. Second, we calculated the optimal Markov-perfect equilibrium policy for this game for all possible industry states and used it to investigate how optimal innovation responds to exogenous changes in market structure.

The structural approach in this paper has a number of advantages over reduced form approaches that look directly at the relationship between innovation and market structure in the data. It allows us to focus on the equilibrium relationships and do away with worries about endogeneity of market structure and reverse causality of innovation on market structure. In fact, the structural approach tackles the endogeneity problem directly by modeling the market structure and its evolution. The structural model can accommodate non-monotonic effects of market structure on innovation, which we can investigate by holding some aspects of market structure constant while varying others. It also allows us to study the relationship across a wide range of industry states, even though only a limited set is observed in the data.

Our approach is also complementary to theoretical work studying the same question. While it is useful to know what type of effects are possible in a model of profit-maximizing firms, it is equally important to know which of these effects are most important in a model where the primitives are estimated from the data. We relied on a functional form for demand and a price setting assumption that are widely used in static models of the automobile sector. The implementation to the global industry necessitated some more assumptions, but the estimated model, in 
particular the dynamic policy vector, is consistent with the observed data.

We learned a number of things. The parameter estimates in the demand, marginal cost, and state transition equations are all plausible. Most, importantly, the model implies average R\&D expenditure of approximately $\$ 1.78$ million per patent and this cost is increasing in the rate of patenting. To fit the data, the model requires a relatively large firm-specific element to the cost of $\mathrm{R} \& \mathrm{D}$.

In terms of the response of optimal innovation to changes in market structure we can highlight the following patterns. First, innovation by the industry leader is strongly decreasing in the efficiency of the lagging firms. Second, holding ownefficiency constant, innovation is decreasing in the dispersion of efficiency in the industry. Third, whether total industry innovation increases or decreases with dispersion of efficiency depends on the specification of marginal production costs. Fourth, higher concentration in efficiency leads to a more than proportional increase in the concentration of innovation. Fifth, innovation is declining in the number of active firms. Sixth, the innovation gap between the leader and other firms increases with competition.

One limitation of the analysis is the assumption of i.i.d. shocks to the cost of $R \& D$ over time. It appears from the data that the innovation level of firms persists over time and this might be the result of persistent shocks to the cost of R\&D. Some firms are consistently better at innovation than others. We did not incorporate persistent shocks, but believe that this is an interesting area for future research. 


\section{References}

Aghion, P., N. Bloom, R. Blundell, R. Griffith, and P. Howitt (2005). Competition and Innovation: An Inverted-U Relationship. Quarterly Journal of Economics 120(2), 701-728.

Aguirregabiria, V. and P. Mira (2007). Sequential Estimation of Dynamic Discrete Games. Econometrica 75(1), 1-53.

Anderson, S. P., A. de Palma, and J.-F. Thisse (1992). Discrete Choice Theory of Product Differentiation. Cambridge, MA: The MIT Press.

Aw, B. Y., M. J. Roberts, and D. Y. Xu (2011). R\&D Investment, Exporting and Productivity Dynamics. American Economic Review 101(3), 1312-1344.

Bajari, P., C. L. Benkard, and J. Levin (2007). Estimating Dynamic Models of Imperfect Competition. Econometrica 75(5), 1331-1370.

Berry, S. (1994). Estimating Discrete-Choice Models of Product Differentiation. Rand Journal of Economics 25(2), 242-262.

Berry, S., J. Levinsohn, and A. Pakes (1995). Automobile Prices in Market Equilibrium. Econometrica 63(4), 841-890.

Blundell, R., R. Griffith, and J. V. Reenen (1999). Market Share, Market Value and Innovation in a Panel of British Manufacturing Firms. Review of Economic Studies 66(3), 529-554.

Boone, J. (2000a). Competitive Pressure: The Effects on Investments in Product and Process Innovation. RAND Journal of Economics 31 (3), 549-569.

Boone, J. (2000b). Intensity of Competition and the Incentive to Innovate. International Journal of Industrial Organization 19, 705-726.

Caplin, A. and B. Nalebuff (1991). Aggregation and Imperfect Competition: On the Existence of Equilibrium. Econometrica 59(1), 26-61.

Carlin, W., M. Schaffer, and P. Seabright (2004). A Minimum of Rivalry: Evidence from Transition Economies on the Importance of Competition for Innovation and Growth. Contributions to Economic Analysis and Policy 3(1), 1-43.

Ching, A. T. (2010). Consumer Learning and Heterogeneity: Dynamics of Demand for Prescription Drugs After Patent Expiration. International Journal of Industrial Organization 28(6), 619-638.

Cohen, W. M. and R. C. Levin (1989). Empirical Studies of Innovation and Market Structure. In R. Schmalensee and R. D. Willig (Eds.), Handbook of Industrial Organization, Volume 2. Amsterdam: North-Holland: Elsevier Science. 
Doraszelski, U. and A. Pakes (2007). A Framework for Applied Dynamic Analysis in I.O. In M. Armstrong and R. Porter (Eds.), Handbook of Industrial Organization, Volume 3, pp. 1887-1966. Amsterdam: NorthHolland.

Ellickson, P. B. and S. Misra (2008). Supermarket Pricing Strategies. Marketing Science 27(5), 811-828.

Ericson, R. and A. Pakes (1995). Markov-Perfect Industry Dynamics: A Framework for Empirical Work. Review of Economic Studies 62(1), 53-82.

Gilbert, R. (2006). Looking for Mr Schumpeter: Where Are We in the Competition-Innovation Debate? In A. B. Jaffe, J. Lerner, and S. Stern (Eds.), Innovation Policy and the Economy (NBER), Volume 6. Cambridge: Massachusetts: The MIT Press.

Goettler, R. and B. Gordon (2009). Competition and innovation in the microprocessor industry: Does AMD spur Intel to innovate more? Working Paper.

Goldberg, P. K. (1995). Product Differentiation and Oligopoly in International Markets: The Case of the U.S. Automobile Industry. Econometrica 63(4), 891-951.

Goldberg, P. K. and F. Verboven (2001). The Evolution of Price Dispersion in the European Car Market. Review of Economic Studies 68(4), 811-48.

Gowrisankaran, G., C. Lucarelli, P. Schmidt-Dengler, and R. J. Town (2009). Government Policy and the Dynamics of Market Structure: Evidence from Critical Access Hospitals. Working Paper.

Griliches, Z. (1990). Patent Statistics as Economic Indicators: A Survey. Journal of Economic Literature 28(4), 1661-1707.

Hall, B. H. (2004). Exploring the patent explosion. Journal of Technology Transfer $30(1-2), 35-48$.

Hotz, J. V. and R. A. Miller (1993). Conditional Choice Probabilities and Estimation of Dynamic Models. Review of Economic Studies 60(3), 497-529.

Jenkins, M., P. Liu, R. Matzkin, and D. McFadden (2004). The Browser War. Econometric Analysis of Markov Perfect Equilibrium in Markets with Network Effects. U.C. Berkeley WP.

Kretschmer, T., E. Miravete, and J. Pernias (2009). Competitive Pressure and Innovation Complementarities. Working Paper.

Pakes, A. and P. McGuire (1994). Computing Markov-perfect Nash Equilibria: Numerical Implications of a Dynamic Differentiated Product Model. RAND Journal of Economics 25(4), 555-589. 
Pakes, A., M. Ostrovsky, and S. Berry (2007). Simple Estimators for the Parameters of Discrete Dynamic Games (with entry/exit examples). Rand Journal of Economics 38(2), 373-399.

Petrin, A. (2002). Quantifying the Benefits of New Products: The Case of Minivan. Journal of Political Economy 110(4), 705-29.

Rust, J. (1987). Optimal Replacement of GMC Bus Engines: An Empirical Model of Harold Zurcher. Econometrica 55(5), 999-1033.

Ryan, S. (2011). The Cost of Environmental Regulation in a Concentrated Industry. Econometrica, forthcoming.

Schumpeter, J. A. (1942). Capitalism, Socialism and Democracy. New York: Harper.

Siebert, R. and C. Zulehner (2010). The impact of market demand and innovation on market structure. Working paper.

Sutton, J. (2008). Market Structure: Theory and Evidence. In M. Armstrong and R. Porter (Eds.), Handbook of Industrial Organization, Volume 3. Amsterdam: North Holland.

Van Biesebroeck, J. (2003). Productivity dynamics with technology choice: An application to automobile assembly. Review of Economic Studies 70(1), 167198.

Vives, X. (2008). Innovation and Competitive Pressure. Journal of Industrial Economics 56(3), 419-469.

Weintraub, G. Y., C. L. Benkard, and B. V. Roy (2008). Markov Perfect Industry Dynamics with Many Firms. Econometrica 76 (6), 1375-1411.

Xu, D. Y. (2008). A structural empirical model of R\&D, firm heterogeneity, and industry evolution. Working Paper. 


\section{Appendix: Implementing the Pakes-McGuire algorithm}

The Pakes-McGuire (PM) algorithm starts with arbitrary value and policy functions $V^{0}$ and $X^{0}$ that are defined over the entire admissible state space. We update these functions pointwise and iterate until they converge to their equilibrium values. The updating goes as follows.

For firm $j$ in state $\left(\xi_{j}, \xi_{-j}, \nu_{j}\right)$, we find its equilibrium level of innovation given $V^{0}$ and $X_{-j}^{0}$. Differentiate the right hand side of the Bellman equation (5) with respect to $x_{j}$ :

$$
\frac{\partial c\left(x_{j}, \nu_{j}\right)}{\partial x_{j}}=\beta \frac{\partial E V^{0}\left(\xi_{j}^{\prime}, \xi_{-j}^{\prime}, \nu_{j}^{\prime}\right)}{\partial x_{j}} .
$$

The functional form for marginal cost in (12) immediately gives the left hand side:

$$
\frac{\partial c\left(x_{j}, \nu_{j}\right)}{\partial x_{j}}=\theta_{x 1}+2 \theta_{x 2} x_{j}+\nu_{j}
$$

To find the derivative on the right, first note that

$$
\begin{aligned}
E V^{0}\left(\xi_{j}^{\prime}, \xi_{-j}^{\prime}, \nu_{j}^{\prime}\right)= & p^{U} E V^{0}\left(\xi_{j}+\Delta_{\xi}, \xi_{-j}^{\prime}, \nu_{j}^{\prime}\right)+p^{S} E V^{0}\left(\xi_{j}, \xi_{-j}^{\prime}, \nu_{j}^{\prime}\right) \\
& +p^{D} E V^{0}\left(\xi_{j}-\Delta_{\xi}, \xi_{-j}^{\prime}, \nu_{j}^{\prime}\right) .
\end{aligned}
$$

The derivative, after some simplification, is then given by

$$
\frac{\partial E V^{0}\left(\xi_{j}^{\prime}, \xi_{-j}^{\prime}, \nu_{j}^{\prime}\right)}{\partial x_{j}}=\theta_{t 2} A e^{-\theta_{t 1}-\theta_{t 2} x_{j}},
$$

where

$$
\begin{aligned}
A= & \left(1-e^{-\theta_{t 3} \tilde{\xi}}\right)\left[E V^{0}\left(\xi_{j}+\Delta_{\xi}, \xi_{-j}^{\prime}, \nu_{j}^{\prime}\right)-E V^{0}\left(\xi_{j}, \xi_{-j}^{\prime}, \nu_{j}^{\prime}\right)\right] \\
& +e^{-\theta_{t 3} \tilde{\xi}}\left[E V^{0}\left(\xi_{j}, \xi_{-j}^{\prime}, \nu_{j}^{\prime}\right)-E V^{0}\left(\xi_{j}-\Delta_{\xi}, \xi_{-j}^{\prime}, \nu_{j}^{\prime}\right)\right] .
\end{aligned}
$$

and $\tilde{\xi}=\left(\xi_{\max }-\xi\right) /\left(\xi_{\max }-\xi_{\min }\right)$. Substituting the two derivatives into the f.o.c. and simplifying, we find an implicit definition of the optimal innovation:

$$
x_{j}^{*}=\frac{1}{\theta_{t 2}}\left[\ln \left(\beta \theta_{t 2} A\right)-\theta_{t 1}-\ln \left(\theta_{x 1}+2 \theta_{x 2} x_{j}^{*}+\nu_{j}\right)\right] .
$$

The left hand side in equation (13) is linearly increasing in $x$ and the right hand side is convexly decreasing because $\hat{\theta}_{x 2}>0$. If the term in square brackets is strictly positive when $x=0$, equation (13) yields a strictly positive and finite equilibrium value $x^{*}$. If the term is negative, we have a corner solution and we set $x^{*}$ equal to zero. We set the standard deviation of the mean-zero error term $\nu_{j}$ to one tenth its estimated value to avoid negative values for the cost of innovation.

Once we know the optimal $x_{j}^{*}$ we can substitute it in the right hand side of the Bellman equation to update the value function:

$$
V^{1}\left(\xi_{j}, \xi_{-j}, \nu_{j}\right)=\pi\left(\xi_{j}, \xi_{-j}\right)-\left(\theta_{x 1}-\theta_{x 2} x_{j}^{*}-\nu_{j}\right) x_{j}^{*}+\beta E V^{0}\left(\xi_{j}^{\prime}, \xi_{-j}^{\prime}, \nu_{j}^{\prime} \mid \xi_{j}, \xi_{-j}, x_{j}^{*}\right) .
$$


"FORD"
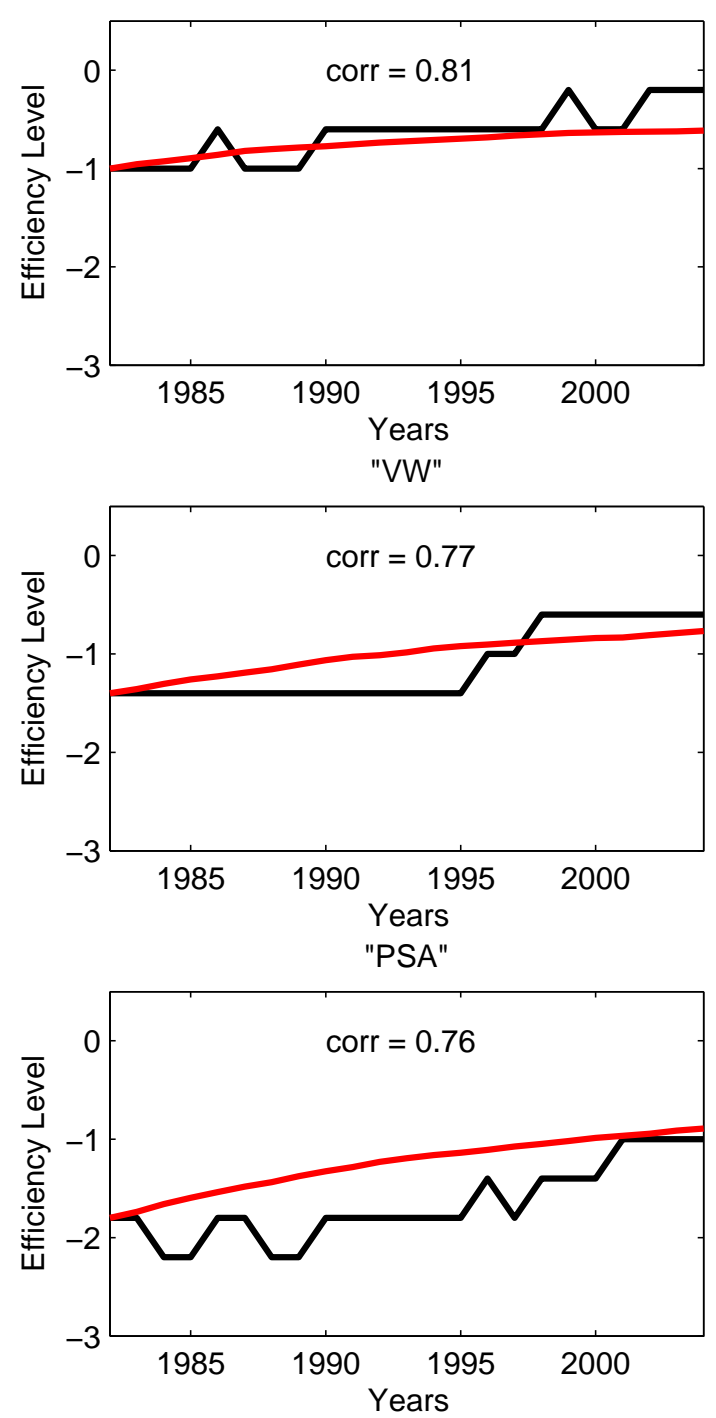

"TOYOTA"

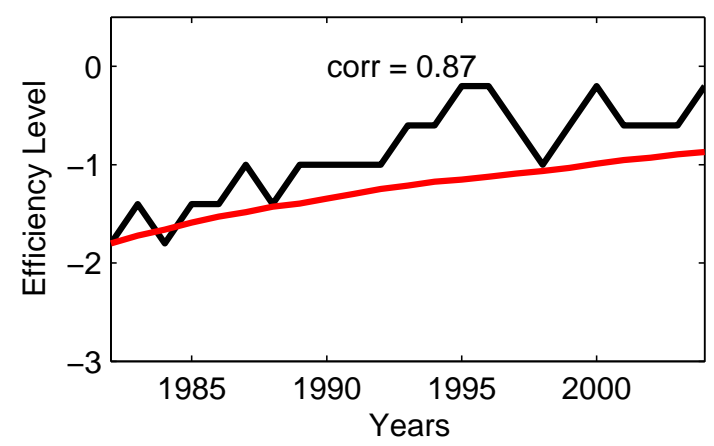

"GM"

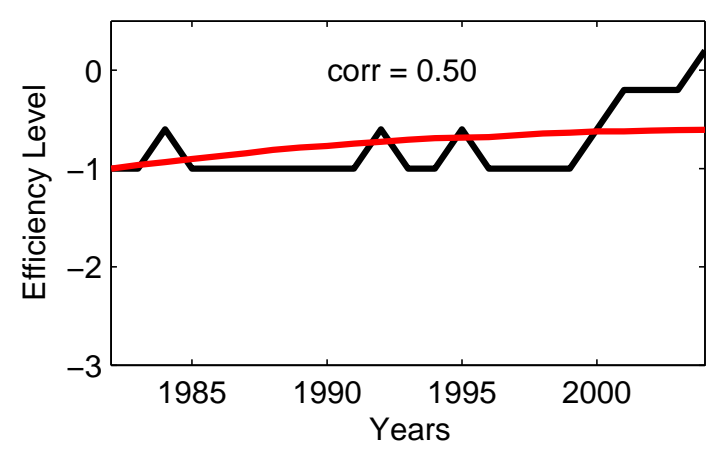

"DAIMLER"

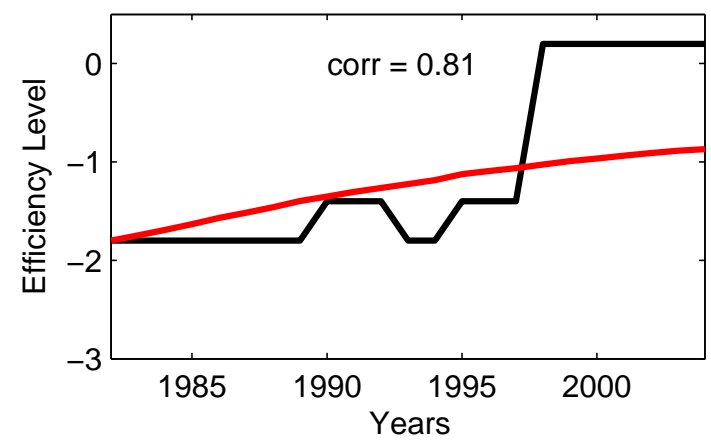

"RENAULT"

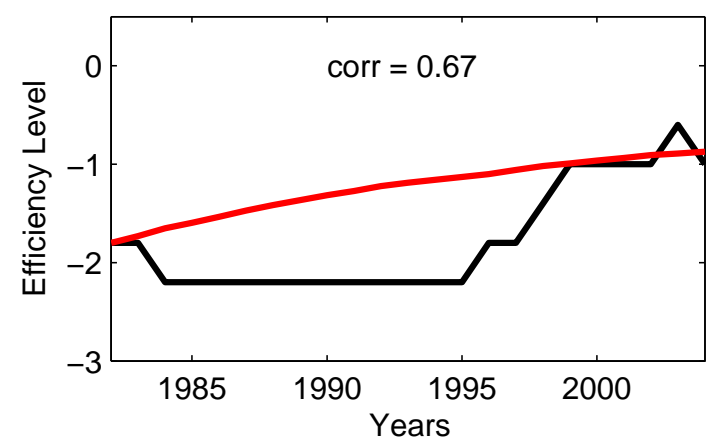

"NISSAN"

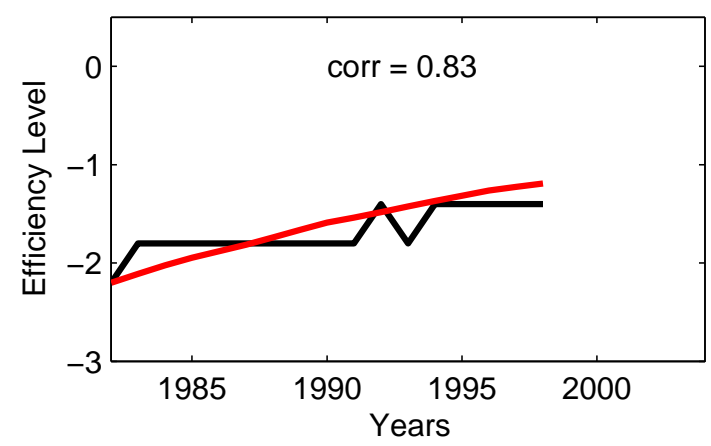

Figure A.1: Evolution of efficiency $(\xi)$ in the model and in the data.

Notes: The black lines show the actual evolution of efficiency for the eight largest firms in the sample. The red lines show the evolution of efficiency when the 1982 industry state is simulated forward using the MPE policy (averaged over one thousand simulations). 


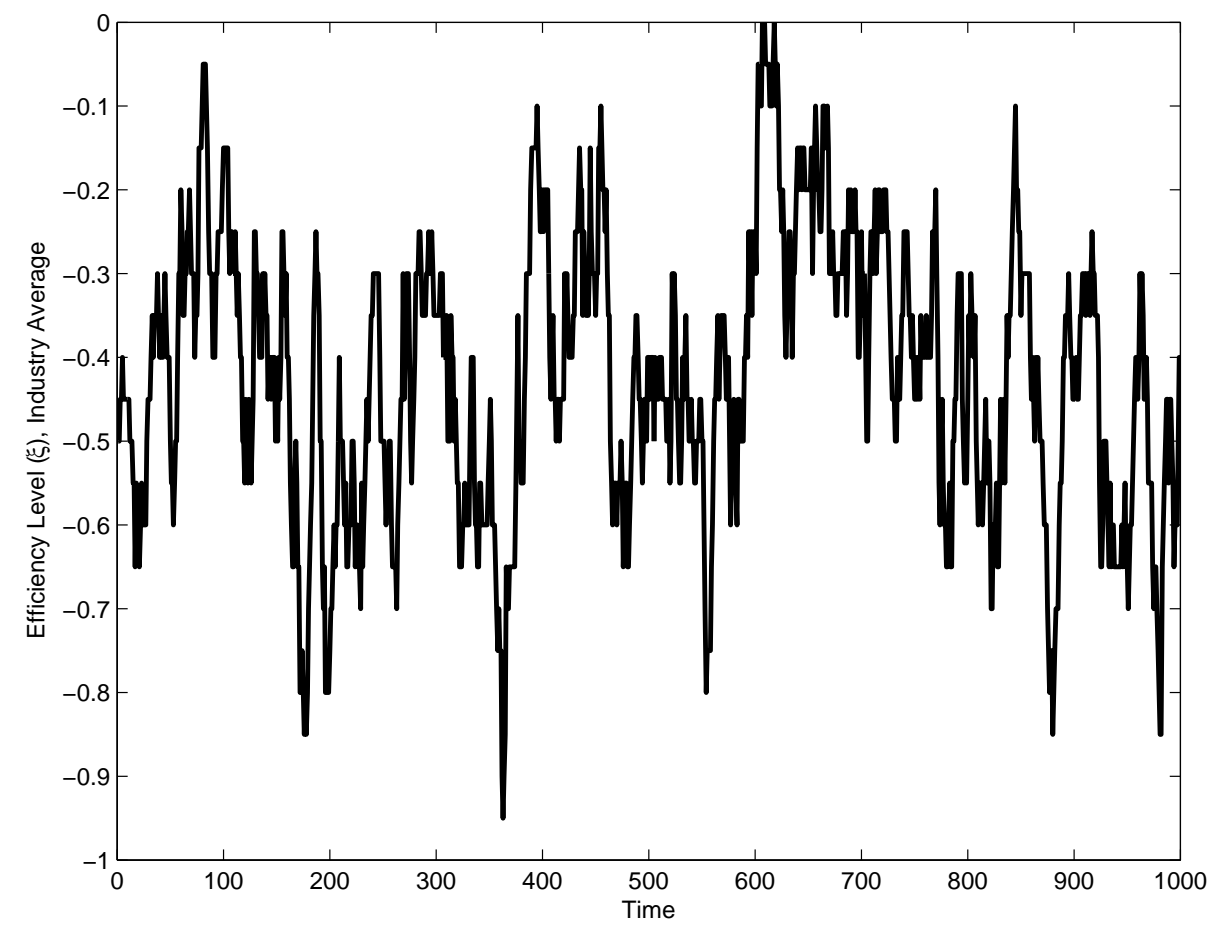

Figure A.2: Evolution of average industry efficiency

Notes: The graph is based on a single forward simulation of the model for one thousand periods. The starting efficiency level is -0.5 for all 8 firms in the model.

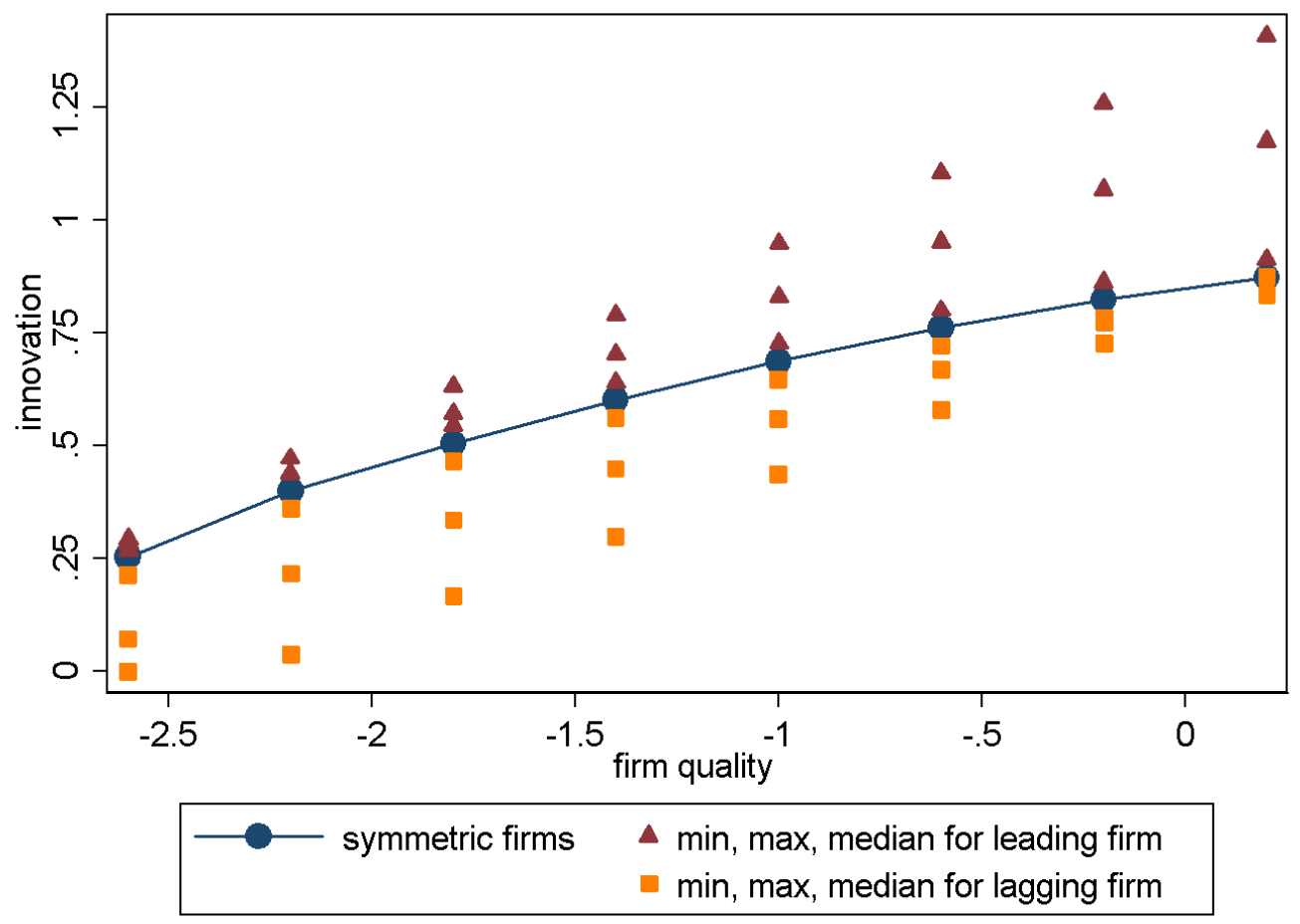

Figure A.3: Innovation as a function of own quality 


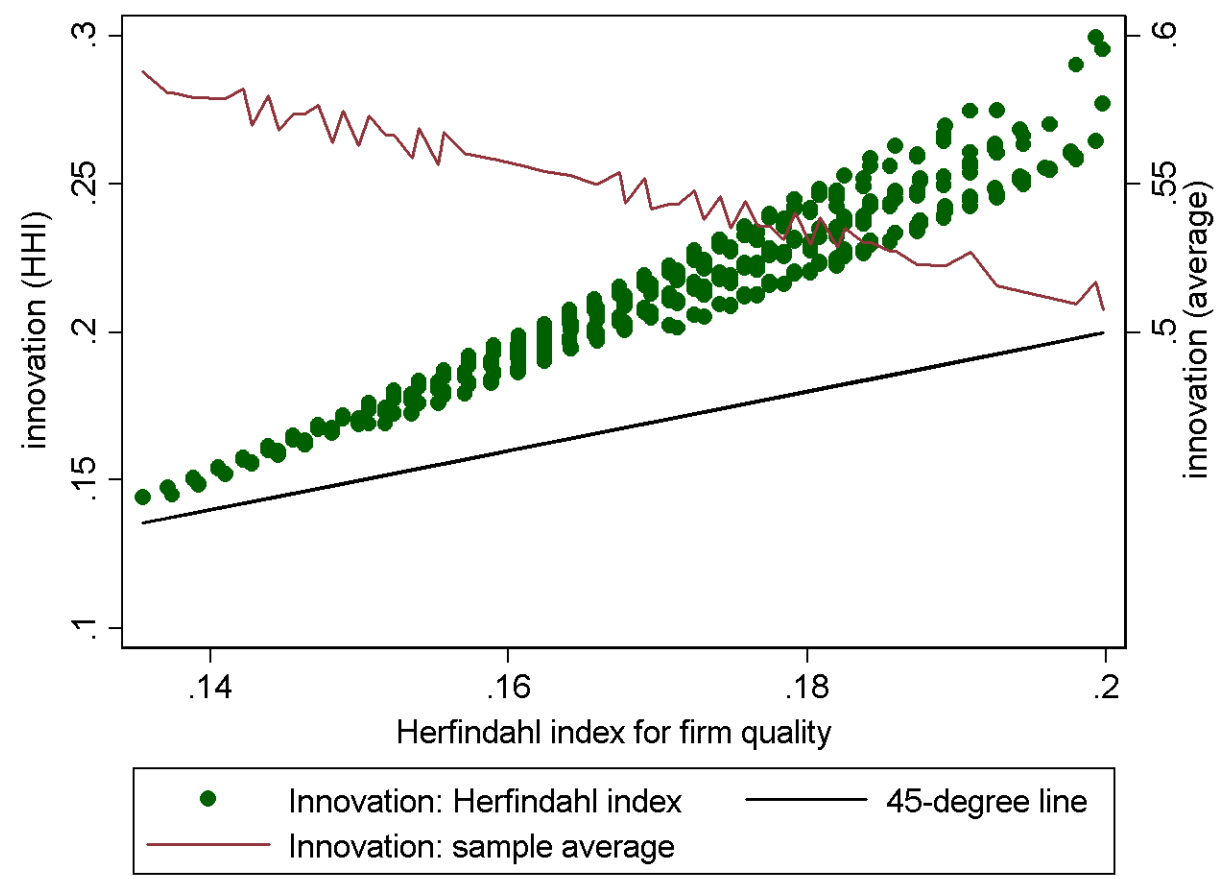

Figure A.4: Concentration of efficiency and innovation

Notes: The concentrations are measured by the Herfindahl indices for firm shares of the state variable (efficiency/quality) and innovation. The average innovation is plotted on the right scale against the quality concentration, holding total industry quality constant.

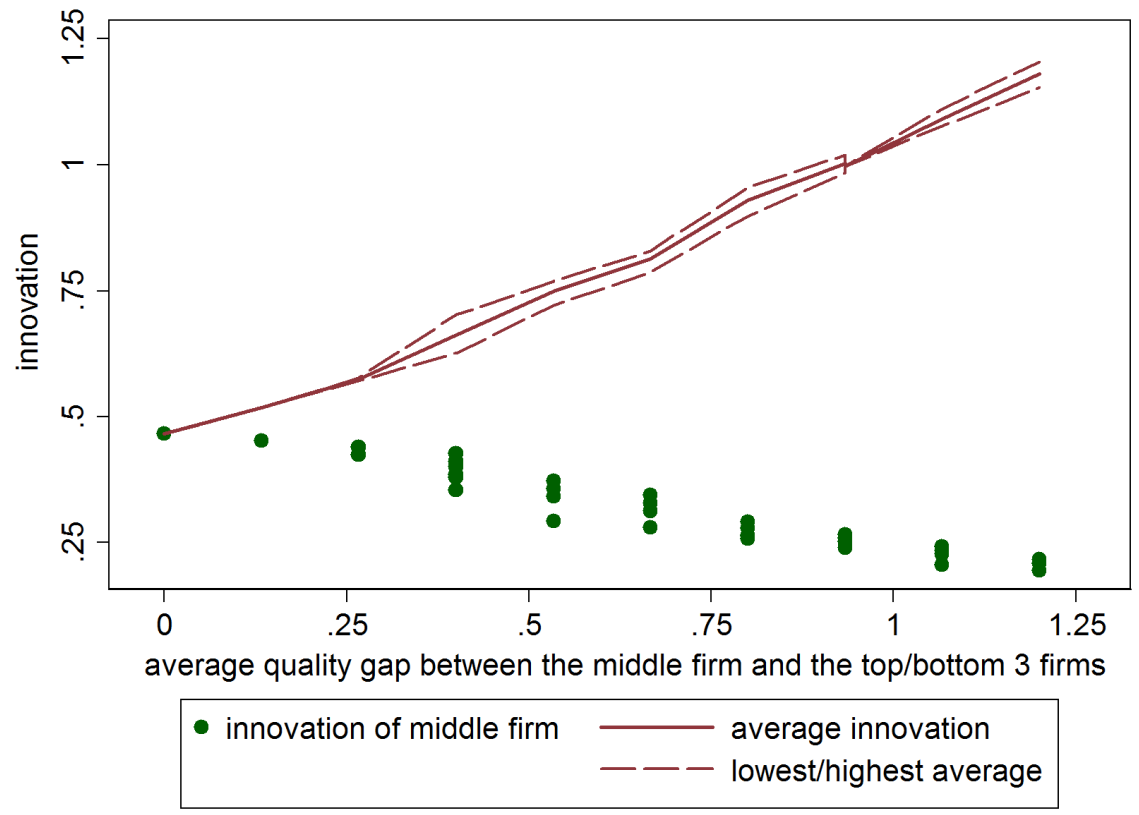

Figure A.5: Innovation as a function of mean-preserving quality dispersion with marginal production costs declining in innovation 
Copyright (c) 2012 @ the author(s). Discussion papers are in draft form. This discussion paper is distributed for purposes of comment and discussion only. It may not be reproduced without permission of the copyright holder. Copies of working papers are available from the author. 